EL EPITOMA REI MILITARIS DE FLAVIO VEGECIO TRADUCIDO AL CASTELLANO EN EL SIGLO XV. EDICION DE LOS «DICHOS DE SENECA EN EL ACTO DE LA CABALLERIA» DE ALFONSO DE CARTAGENA

Por

TOMAS GONZALEZ ROLAN

PILAR SAQUERO SUAREZ-SOMONTE 
Al Dr. Torres Fontes, maestro del medievalismo bispánico.

El renovado interés que la Edad Media ha suscitado entre los estudiosos desde hace algunos años ha permitido a los filólogos clásicos cambiar algunos de sus puntos de vista más arraigados. Así ya no se puede seguir hablando de gran vacío entre la civilización antigua y la época renacentista sino de continuidad ininterrumpida entre ambas precisamente a través del Medievo.

Hoy se puede asumir e incluso ampliar la tesis de Jean Seznec (1) de que cuanto más se profundiza en esa época use cae en la cuenta, sobre todo, de que la Antigüedad pagana, lejos de «re-nacer» en la Italia del siglo $\mathrm{XV}$, había sobrevivido en la cultura y el arte medievales; los dioses mismos no resucitan, puesto que nunca desaparecieron de la memoria y la imaginación de los hombres».

Si de la mitología pasamos a otros campos de la cultura antigua, podemos igualmente comprobar no sólo su supervivencia en la Edad Media, sino incluso su verdadero esplendor, como es el caso de la ciencia militar.

(1) Los Dioses de la Antigüedad en la Edad Media y el Renacimiento, Madrid, 1983, p. 11. 
Las continuas guerras que en este período tuvieron lugar dejaron su huella no sólo en la arquitectura (castillos, ciudades amuralladas etc.) sino también en la creación de un particular ideal de vida que conocemos con el nombre de caballeresco.

Y si bien uno de los rasgos más significativos y propiamente medievales del caballero andante es el individualismo, otros como la disciplina y el entrenamiento en su dedicación profesional parecen deberse al influjo ejercido por la antigüedad clásica.

A ella se dirigió el Medievo con la finalidad de adquirir conocimientos que mejorasen y perfeccionasen su preparación táctica o estratégica, con la que poder enfrentarse en condiciones ventajosas al enemigo. Pero no sólo se perseguía un fin práctico, sino también un interés teórico, en el convencimiento de que las hazañas realizadas por los antiguos podían servirles de ejemplo y sacar enseñanzas de ellas.

Desde este punto de vista no es de extrañar el arraigo y popularidad en la Edad Media de una obra como la de Vegecio. Los hombres la leían, nos dice M. Keen (2), porque sabían que los romanos habían conquistado el mundo y deseaban saber cómo lo habían logrado: «de la historia clásica y de tratados como los de Vegecio, la caballería extraía lecciones que ni la épica ni la narrativa (ni la mitología en lo tocante a esto) podían enseñar de manera tan eficaz. Aquí, los hombres encontraron un nuevo significado en la disciplina y en el entrenamiento: que el militar bisoño necesitaba mantener su físico en buen estado, y que el soldado en campaña debía obedecer las órdenes de su superior».

Ahora bien, la razón por la que sonrió tanto la fortuna precisamente al Epitoma rei militaris de Vegecio hay que buscarla no en su

(2) La caballeria (versión castellana de Elvira e Isabel de Riquer, Prólogo de Martín de Riquer), Barcelona, 1986, p. 150. 
calidad literaria, sino en que es el único testimonio importante que la Antigüedad legó sobre ciencia militar. Esta obra realizada (3) casi con toda seguridad a finales del s. IV, quizás bajo Teodosio, es un compendio o resumen obtenido de otros tratados militares de autores latinos anteriores a él, como Catón, Celso, Frontino etc.

Aunque originalmente estaba dividida en cinco libros, como piensa L. Rubio (4), la vulgata, apoyada por la mayoría de los manuscritos, ha fundido el cuarto y quinto en un solo libro, y así, después del título incluye un resumen de lo que trata cada uno de estos cuatro libros: el primero de la selección y adiestramiento de los reclutas (Primus liber electionem edocet iuniorum, ex quibus locis uel quales milites probandi sint aut quibus armorum exercitiis imbuendi); el segundo de la organización del ejército de tierra (secundus liber ueteris militae continet morem ad quem pedestris institui possit exercitus); el tercero de las disposiciones tácticas para entrar en combate (Tertius liber omnia artium genera quae in terrestri proelio necessaria uidentur exponit); el cuarto de los instrumentos (ingenios) de la defensa y ataque de las ciudades, así como de las normas del combate naval (Quartus liber uniuersas machinas quibus uel oppugnantur ciuitates uel defenduntur enumerat; naualis quoque belli praecepta subnectit).

De lo dicho hasta aquí se puede ver con claridad que el Epitoma rei militaris ofrece al examen de los filólogos dos vertientes, una como obra técnica inserta dentro de la literatura latina y por ello objeto de estudio, por sí misma, en el que se incluyen los problemas de las

(3) Sobre el difícil problema de la datación y finalidad del De re militari pueden consultarse los recientes trabajos de Claudia Giuffrida, "Per una datazione dell'Epitoma rei militaris di Vegezio. Politica e propaganda nell'etá di Onorio», en Siculorum Gymnasium, N.S.a. XXXIV, 1981, 25-56; de W. Goffart, "The date and purpuse of Vegetius De re militari", Traditio 3.3, 1977, 65-100; y de A. Marcone, "Il de re militari di Vegezio», en Studi e Ricerche dell'Ist. di Storia, Fac. di Lettere e Filosoffa, Univ. di Firenze, I, 1981, 121-138.

(4) "Nuevos datos para una edición del Epitoma rei militaris», Emerita, XI.I, 1973, 209-223. 
fuentes utilizadas, la época en que fue escrita, número de libros, finalidad, etc. etc.; y otra como manual de ciencia militar profusamente utilizado y repetidas veces traducido en el Medievo.

La atención a lo que podríamos llamar Vegecio latino tuvo una época dorada a finales del siglo pasado y en parte a comienzos del actual. En ese tiempo se realizaron trabajos tan importantes como los de H. Brucke (5), Ch. Schöner (6), J.W. Förster (7), O. Seeck (8), M. Manitius (9), Th. Mommsen (10), E. Sander (11), A. Andersson (12 y sobre todo C. Lang (13), autor de la primera y más rigurosa edición crítica de nuestro autor.

La falta de interés por Vegecio que ya se apunta en los primeros treinta años de nuestro siglo se convierte en total despreocupación en los cuarenta años siguientes hasta la década de los setenta, en la que, coincidiendo con el despertar de los estudios medio-latinos, comienzan los intentos de nuevas ediciones que sustituyan a la ya anticuada de Lang. En este sentido podemos señalar las de L. F. Stelten (14), D.K. Silhanek (15), A. Komornicka (16), y particularmente las de

(5) Quaestiones Vegetianae, Diss. Leipzig 1875.

(6) Studien zu Vegetius, Erlangen 1880.

(7) De fide Flavii Vegetii Renati, Diss. Bonn 1879.

(8) “Die Zeit des Vegetius», Hermes XI, 1876, 61-83.

(9) "Aus Dresdener Handschriften: I. Scholien zu Vegetius», RhM LVII, 1902, 392-397.

(10) «Zu Vegetius», Hermes I, 1866, 130-133.

(11) «Frontin als Quellen für Vegetius», Ph. W XLIX, 1929, 1230-1231; «Die Hauptquellen der Bücher I-III der Epitoma Rei Militaris des Vegetius», Philologus, LXXXVII, 1932, 369-375.

(12) Studia Vegetiana, Upsala 1938.

(13) Fl. Vegetii Epitoma rei militaris, Teubner, Leipzig 1885.

(14) Epitoma rei militaris of Flavius Vegetius Renatus: $A$ critical edition of books $I$ and II (Latin with preface in english), Universidad de S. Louis, Missouri 1970.

(15) Vegetius Epitoma, Books 1 and 2. A translation and commentary, Diss., New York University 1972.

(16) Epitoma rei militaris, I-II, trad. en polaco, Meander XXVIII, 1973, 403-517; 485-501; III-IV, Meander, XXIX, 1974, 198-232; 333-352. 
M. Teresa Callejas Berdonés (17) y M. Felisa del Barrio (18), en las que junto con los más antiguos e importantes manuscritos europeos se colacionan y estudian por primera vez todos los valiosos códices de las bibliotecas españolas, consiguiendo así la edición más completa existente en la actualidad.

Además de estas ediciones podemos señalar también los artículos de C. E. Finch (19) y L. Rubio (20) sobre aspectos concretos de la transmisión, y los ya citados y más recientes de W. Goffart, A. Marcone, C. Giuffrida, referentes a distintos aspectos literarios que la obra de Vegecio plantea.

$\mathrm{Y}$ sin embargo a pesar de ser el Epitoma rei militaris una de las obras de la antigüedad más leídas y traducidas en el Medievo, no ha recibido atención adecuada por parte de los filólogos, hasta el punto de que J.A. Wisman (21) ha podido hacer la siguiente afirmación: "Aucune étude n'a jusqu'ici essayé de montrer l'importance et l'influence de l'oeuvre de l'auteur latin au Moyen Age et c'est notre but de remédier à cette carence».

Afirmación, en cierta medida, atrevida e injustificada porque tres años antes de su trabajo un americano, Charles Reginald Schrader (22), había escrito un grueso volumen en el que investigaba la distribución de los manuscritos latinos de Vegecio en las distintas na-

(17) Edición critica y traducción del Epitoma rei militaris de Vegetius, libros I y II, a la luz de los manuscritos españoles y de los más antiguos testimonios europeos. Madrid, 1982.

(18) Edición critica y traducción del Epitoma rei militaris de Vegetius, libros III y IV, a la luz de los manuscritos españoles y de los más antiguos testimonios europeos, Madrid 1982.

(19) "Codices Pal.Lat. 1571-1573 as sources for Vegetius", TAPhA XCIII, 1962, 22-29; "Source of codex E of Vegetius», CB, XLI, 1965, 45-46.

(20) Op. cit. (cf. nota 4).

(21) «L'Epitoma rei militaris de Végèce et sa fortune au Moyen Age», en Le Moyen Age, LXXXV, 1979, 13-31; p. 13.

(22) Ch. Schrader, The Ownership and Distribution of Manuscripts of the De re militari of Flavius Vegetius Renatus before the year 1300, Columbia University, Ph. D. 1976. 
ciones de Europa, dedicando además amplios apartados a las distintas traducciones hechas de esta obra.

El mismo C.R. Schrader publicaba tres años más tarde una completa lista (23) de los manuscritos latinos de la obra, así como los que contienen las traducciones en francés, inglés, italiano, español, alemán, e incluso bilingües: latín-italiano, lạtín-hebreo, latín - anglo normando - francés.

Schrader cataloga, entre los siglos IX-XV, nada menos que 243 códices latinos, 46 de distintas traducciones al francés, 17 al inglés, 10 al italiano, 2 al español, 2 al alemán y 3 en más de una lengua.

2. Ciñiéndose ahora a la presencia de Vegecio en España será oportuno señalar que no nos detendremos en lo que hemos llamados Vegecio latino, sea completo, pues ya ha sido estudiado por las citadas M. Teresa Callejas y M. Felisa del Barrio, o abreviado, el que figura en los códices con el nombre de Cicerón, Catón o Modesto, cuya edición crítica hemos preparado y está a punto de ver la luz (26), ni en

(23) «A handlist of extant manuscripts containing the De re militari of Flavius Vegetius Renatus", Scriptorium XXXIII, 1979, 280-305.

(24) "Vegetius im Mittelalter», Philologus CXXIII, 1979, 85-90.

(25) Studies in medieval uses of Vegetius Epitoma rei militaris, Diss. Univ. of California Los Angeles 1980.

(26) T. González-Ana Moure, "Edición del De re militari de Modesto», en Homenaje a L. Rubio, Cuadernos de Filología Clásica (de próxima aparición). Sobre este extracto del Epitoma escribió un interesante trabajo a comienzos de siglo L. Dalmasso, "La storia di un estratto di Vegeziom, en Rendiconti del Istituto Lombardo di Scieze e lettere, 1907, 805-814, en el que trata de demostrar que este opúsculo, tomado de Vegecio, remonta a los siglos XIII o XIV, cuando la amplia difusión de su obra hizo oportuno un extracto o resumen que agilizase su uso. La más antigua atribución lleva el nombre de Cicerón (Cicero de re militari) y el primer testimonio de ello se debe a Petrarca, quien en sus Epistolae de rebus familiaribus (XXIV, 4) habla de las obras de Cicerón y entre ellas de un De re militari. Más tarde aparece en los códices atribuido a Catón y a un tal Modestus. En la Biblioteca del Escorial conservamos doș códices de este resumen junto con las obras de Cicerón (O. II. 12. fol. 75v: Marci Tulli ciceronis de re militari incipit liber; R. I. 2, fol. 193r: Incipit liber tullii de re militari) 
el conocimiento que de él tuvieron los distintos autores medievales, que debió ser amplio a juzgar por las palabras de Juan Alfonso de Baena (27):

\author{
Yo ley en el Vegecio, \\ que compuso las batallas, \\ el que supo asi pintallas \\ et las puso en grande presçio,
}

sino tan sólo en las traducciones castellanas (28) del siglo XV, ya sean completas, parciales o resumidas.

Ch. R. Shrader se refiere, como hemos dicho, a las distintas traducciones hechas en Europa del Epitoma. Y en el apartado dedicado a España dice lo siguiente (29): «The de re militari was first translated into Spanish in the fifteenth century. Two manuscripts in the Escorial contain a Castilian Spanish translation of Vegetius entitled "El libro de Vegecio de la cavalleria", made by Fra Alonso de San Cristobal, O.P., and dedicated to king Henry of Leon and Castile. The first of these, MS. II.18, may have belonged to Isabella the Catholic. The second, MS. P.I.23, came to the Escorial from the library of the Conde Duque de Olivares. Insofar as I have been able to ascertain, these are the only appearances of Vegetius' treatise in the Spanish language

(27) Cancionero de Gallardo, fol. 33v, citado por J. Amador de los Ríos, Historia critica de la literatura española (Ed. facsimil), Madrid 1969, t. VI, p. 325, n. 1)

(28) Sobre una traducción al catalán, no conocida por J. A. Wisman ni por Schrader, ha crito un magnífico trabajo L. Badia, "Fronti $i$ Vegeci, mestres de cavalleria en catalá als segles XIV i XVm, en Boletín de la real Academia de Buenas Letras de Barcelona, XXXIX, 1983-1984, 191-212, en el que demuestra que los lectores catalanes del XIV y $\mathrm{XV}$ conocian y apreciaban a los tratadistas clásicos de tema militar, Frontino y Vegecio: "els coneixien tant que se'ls llegien en català per a poder los manejar millor, i els apreciaven tant que els veien com uns mestres de cavalleria que havien concebut en l'antigor les seves obres per a subenir a las necessitats de les guerres que ells estaven fent. En aixó els lectors catalans, d'altra banda, eren perfectament homologables, com veurem, amb la gran majoria dels altres lectors europens del moment».

(29) Ch. R. Schrader 1976, pp. 121-122. 
until the publication of Jaime de Viana's translation at Madrid in 1764 , which is itself apparently the only modern Spanish translation ever made».

Por su parte J.A. Wisman sin citar el nombre del autor da cuenta de dos manuscritos castellanos en la Biblioteca Nacional de París (30): "Il existe à la Bibliothèque Nationale de Paris 2 manuscrits du texte de Végèce en castillan. Le premier, Anc. f. 7807, est intitulé "Vegeçio de las batallas»; c'est un manuscrit du XVe siècle dont le contenu est divisé en 4 livres. La plupart des chapitres sont suivis de gloses tirées d'auteurs latins ou de livres de la Bible. Le deuxième, Suppl. franç. 3148, est une copie du précedent, mais sans gloses».

Se trata, en efecto, de la versión castellana del Epitoma rei militaris a la que se le añade glosas tomadas de distintos textos paganos y cristianos y una aplicación moral, realizada por el dominico fray Alonso de San Cristóbal a petición (31) del rey Enrique IV de Castilla y León (32), tal como nos cuenta el propio autor en el prohemio de su obra (33):

[fol.1r] «Aqui comiença el libro de vegeçio de la caualleria el qual libro se contiene como se han de fazer las guerras e batallas de todas las huestes e de otras cosas mucho prouechosas tocantes a los grandes rreyes e prinçipes a a todos los otros estados [de mano y letra diferentes

(30) Op. cit. p. 21.

(31) P. Russell, en su excelente obra Traducciones y traductores en la Peninsula Ibérica (1400-1500), Universidad Autónoma de Bellaterra, Barcelona 1985, 33-34 piensa que la traducción fue probablemente emprendida por orden de Enrique III de Castilla y no por Enrique IV como tradicionalmente se ha venido sosteniendo. Para la fundamentación de este aserto remite a un trabajo en prensa que no sabemos ni dónde y cuándo ha aparecido.

(32) Además de los códices citados por Schrader y $\mathrm{W}$ isman podemos añadir dos más, uno incompleto, de la Biblioteca Nacional de Madrid, 10445, fols. 151r-157, ya conocido por M. Schiff (La Bibilotbéque du Marquis de Santillane, París 1905, reimpr. Amsterdam 970, pp. 75-76), y otro, completo, de la Biblioteca Menéndez y Pelayo de Santander (n.0 351).

(33) El texto que reproducimos está tomado del códice \&-II-18 de El Escorial, fols. $1 \mathrm{r}-2 \mathrm{r}$ 
y más recientes: glosado por fray Alonso de St Christoual y acomodado al sentido y guerra spiritual por el mismo.]

Muy alto e muy noble e muy claro prinçipe poderoso rrey e señor don Enrrique por la graçia de dios rrey de Castilla, de Leon, de Toledo, de Gallizia, de Seuilla, de Cordoua, de Murçia, de Jahen, del Algarve, de Algezira, e señor de Viscaya e de Molina, a quien dios dexe veuir a rreynar por muchos tiempos e buenos a su seruiçio, amen. Yo frey Alfonso de Sant Christoual maestro en santa theologia, vuestro seruidor e vuestro criado a orador deuoto beso humill mente vuestras manos e me en comiendo en vuestra alta señoria e merçed como a mi señor natural.

\section{Prologo IIo}

Señor, por quanto fue vuestra merçed de me mandar rromançar en nuestro lenguaje el libro e la obra que fizo Vegeçio de la caualleria [fol. 1v] e del arte de las batallas, e yo veyendo e considerando que non solamente avedes vos e han todos los fieles católicos batalla corporal en tierra con los enemigos que veemos que son corporales, mas avn contra los enemigos que non vemos, que son espirituales, segund dixo el apostol Sant Pablo en la apistola que enbio a los de Epheso en el capitulo sesto a do dize: Non est nobis colluccosio aduersus carnen scilicet solum sed aduersus prinçipes et potestates tenebrarum qui babitant in çelestibus, que quiere dezir que non sola mente auemos guerra contra los prinçipes e poderios que moran en el ayre tenebroso que son los enemigos del anima. Otrosi considerando que en el fecho de la caualleria e de las peleas non sola mente fablo Vegeçio, mas otros muchos sabidores dixeron muy muchas cosas en sus rrazon que concuerdan con lo que dixo Vegeçio. Por ende ayudandome el señor dios pense de partir esta obra en tres partes: la primera parte fablara e dira lo que dixo Vegeçio en sus libros rromançandolos lo mas clara mente que yo pudiere; la segunda parte sera como glosa puesta en la margen del libro que es de dichos de los sabidores que concuerdan con lo que dize Vegecio e declara sus dichos en algunos lugares e la terçera 
[fol. 2r] parte sera puesta ayuso que fablara espiritual mente trayendo los dichos de Vegeçio a las vezes virtudes e a los pecados e a las costunbres desta vida en que beuimos. E ansy sera esta obra en algunos lugares de batalla espiritual porque non sola mente sepades, Señor, qual es la çiençia del pelear corporal mente mas espiritual mente en manera que el vuestro espiritu se deleyte en el señor dios que es vida perdurable para sienpre en guisa que rregnedes en esta vida por muchos tienpos al su seruiçio e despues en la otra vida que es perpetua por infynita secula amenn.

Como puede deducirse del proemio, Alfonso de San Cristóbal, buen conocedor del latín, pretende en su traducción la claridad ("e dira lo que dixo Vegeçio en sus libros rromançando los lo mas clara mente que yo pudiere»), lo que parece conseguir, puesto quecomo ha señalado P. Russell (34) «se halla redactada en un castellano sencillo y directo, pero también dúctil y bien dotado de recursos expresivos».

Y esta claridad está sin duda en función de un fin eminentemente didáctico y moralizante, que el autor quiere dar a su obra, a saber mostrar la doble batalla que libra el cristiano en este mundo, contra los enemigos corporale y contra los enemigos espirituales: « $\mathrm{E}$ ansy sera esta obra en algunos lugares de batalla espiritual porque non sola mente sepades, Señor, qual es la çiençia del pelear corporal mente mas espiritual mente...»

La traducción debió conseguir cierto arraigo a juzgar por los seis códices que conocemos de ella y de un hecho hasta el momento ignorado, que pasamos a referir.

En efecto, un estudioso tan conocedor de la literatura medieval española como A. D. Deyermond (35) en el capítulo dedicado a la prosa de los siglos XIV y XV incluye entre las obras de Don Enrique

(34) Op. cit. p. 33.

(35) Historia de la literatura española, I, La Edad Media, Barcelona 1974, p. 263. 
de Villena un Libro de la Guerra, según él «una versión bastante fiel del De re militari de Vegecion.

Como obra de Villena fue editada por Lucas de Torre (36), quien en la advertencia preliminar nos habla de su valor: «Si la obra, como parece indicarlo la portada, es verdaderamente de Don Enrique, su importancia es grande, pues nos muestra un nuevo aspecto de aquel magnate cuya ilustración y conocimientos eran superiores a los de la mayor parte de las personalidades de su tiempo, y si no lo es, no por eso pierde su importancia, pues, perdidas las obras militares del Infante Don Juan Manuel, queda ésta que nos ocupa como la primera obra militar escrita en español (37), ya que, por el carácter de letra y demás circunstancias que en ella concurren, ha tenido que ser escrita en la primera mitad del siglo XV».

Las dudas que el mismo Lucas de Torre se plantea sobre la autoría de Villena ha sido definitivamente despejadas en sentido negativo por Derek C. Carr (38) al demostrar que la conexión del Libro de la Guerra con Enrique de Villena se debe exclusivamente a compartir con una copia de los Doce trabajos de Hércules los folios del códice 6526 del siglo XV, "cuya portada original fue sustituida en el siglo XVIII por otra llena de errores, entre los cuales figura la atribución de la obra a don Enrique (39)».

Mientras el argumento aducido por Derek C. Carr es «externo", el que ahora presentamos nosotros desvelerá definitivamente si la obra es o no de Enrique de Villena.

(36) "El libro de la guerra», en Revue Hispanique, XXXVIII, 1916, 497-531; lo edita siguiendo el ms. 6526 de la Biblioteca Nacional de Madrid, fols. 61v-85v.

(37) El subrayado es nuestro.

(38) Enrique de Villena, Tratado de la Consolación, Madrid 1977, p. LV.

(39) En el folio $1 \mathrm{r}$ aparece esta portada en letras mayúsculas: "Trabaxos de ercules y libro de la guerra compuesto por el Sr Dn Enrique de Aragón Marqués de Villena a ynstancias de Pedro Pardo caballero Catalan, en Valencia en el año del Sr. MCCCCXX». 
Para empezar digamos que El libro de la guerra no es una versión bastante fiel del De re militari, como creía Deyermond, sino una traducción del libro tercero a la que acompañan preliminarmente un prólogo y una exposición de intenciones, en la que el autor nos dice: «Empieça el libro de la guerra, que escribo por utilidad i beneficio de todos, y principalmente para caballeros a quienes perteneçe mas por raçon de la nobleça e buen gobierno, cuidando en las batallas de saber offender e defender, ganando premio, honrra e gloria».

Estas palabras del supuesto autor son sin duda la única aportación personal porque el resto, es decir el prólogo y los treinta y seis capitulos de que consta la obra, estan calcados, tomados, copiados o como se quiera decir nada más y nada menos que de la traducción de Alfonso de San Cristóbal.

Este es el argumento decisivo, creemos, para negar la autoría del Libro de la guerra a Don Enrique de Villena.

Después del prohemio dirigido al rey Don Enrique, Alfonso de San Cristóbal se detiene a considerar la estructura y división que presenta la obra de Vegecio (fol. 2r): "La primera parte e obra es declarar e rromançar los libros e los dichos de Vegeçio segund lo que el dize. E por ende es de saber que Vegeçio toda su obra parte en quatro libros e cada libro faze vn prologo que es como arenga segund costunbre de los sabios que ponen obra e ante que venga a tratar en estos libros faze vn prologo comun a toda la arte e vna arenga en alabança de la çiençia e arte de la caualleria.

El prólogo común a todos los libros suyos e a toda la arte es este que se sigue».

El prólogo general que a continuación inserta Alfonso de San Cristóbal no es el que figura en los códices latinos, sino el capítulo diez del libro tercero. Sin duda el original latino utilizado por nuestro 
traductor tenía ya este cambio y él se limitó a verter al castellano el modelo que tenía ante los ojos.

Ahora bien, el «autor» del Libro de la guerra comienza su obra con un prólogo que reproduce igualmente el capítulo diez del libro tercero.

El anónimo autor reproduce el prólogo general que encuentra en la traducción de Alfonso de San Cristóbal y a continuación los capítulos del libro tercero no de forma completa sino resumida respecto al texto de Alfonso de San Cristóbal.

Veamos los ejemplos que nos ofrecen los capítulos primero y último de este libro tercero.

Vegecio comienza de este modo (III,I) el capítulo primero (40):

Primus liber tironum dilectum exercitiumque deprompsit, sequens legionis institutionem disciplinamque edocuit militarem, hic tertius classicum sonat. Ideo enim illa praemissa sunt, ut haec, in quibus peritia certaminum et uictoriae summa consistit, disciplinae ordine custodito et intellegerentur celerius et amplius adiuuarent.

Exercitus dicitur tam legionum quam etiam auxiliorum nec non etiam equitum ad gerendum bellum multitudo collecta. Huius modus a magistris quaeritur armorum. Nam cum Xerxis et Darii uel Mithridatis ceterorumque regum, qui innumerabiles armauerant populos, exempla releguntur, euidenter apparet nimium copiosos exercitus magis propria multitudine quam bostium uirtute depressos. Nam pluribus casibus subiacet amplior multitudo...

Este texto latino es vertido al castellano de la manera siguiente:

(40) Cada vez que citamos a Vegecio lo hacemos siguiendo el texto establecido por las citadas M.a Felisa del Barrio y M.a Teresa Calleja. 
A. de San Cristóbal

$(§-I I-18$, fol.60v- $61 r)$

El primero libro fablo e mostro el escogimiento de los mançebos e para componer e basteçer la hueste, e el segundo libro mostro la hordenança de la arte e sabiduria de la caualleria, e el terçero libro declara ya la obra de la batalla qual es ca por eso son ya aquellas cosas dichas primera mente por que estas que se agora diran se entendiesen mejor e mas conplida mente e las primeras ayudanse a estas en que esta la sabiduria de las peleas, e la postrimera vitoria guardando la orden de la arte susodicha. Veamos agora que cosa es hueste. Hueste es muchedumbre ayuntada de gentes de cauallo e de pie para fazer batalla e asy lo dixeron los maestros e dotores de las armas e sy los exenplos leyeremos de Xerses e de Dario e de Ponpeo e de Mitridas e de otros reyes que ayuntaron e armaron pueblos syn cuento, manifiesta mente paresçiera que muchas huestes abastadas de muchas gentes fueron vençidas mas por ser muchas que no por fuerça e virtud de los enemigos e la rrazon lo dize ca por muchas maneras lo pasa peor la mas gente e mayor muchedunbre...

\section{Libro de la Guerra}

(ed. de Lucas de Torre, p. 499-500)
Hueste es muchedumbre ayuntada de gente de cauallo e de pie e asy lo dixieron los maestros de la armas; e si los fechos leyeremos del rey Xerces, e de Dario, e de Poro, e de otros reyes que ayuntaron pueblos sin cuento, magnifiestamente paresçiera que las grandes huestes abastadas de muchas gentes por mengua de buena ordenança son muy aynas vençidas mas por mengua de aquella que por fuerça $e$ virtud de los enemigos. Ansy mismo la muchedumbre de las gentes por muchas maneras lo pasa peor... 
No hay que esforzarse demasiado para darse cuenta de que la traducción de A. de San Cristóbal sigue el modelo latino, mientras que la del Libro de la guerra parece un resumen, ligeramente modificado, de aquella. Se podría cotejar cualquiera de los treinta y seis capítulos del Libro de la guerra con la versión de A. de San Cristóbal y la impresión seguiría siendo la misma: el primero copia al segundo, sometiendo su modelo a drásticas simplificaciones y a algunos cambios léxicos y sintácticos. Para que no haya duda de la vinculación de los dos textos, confrontaremos algunos pasajes del último capítulo del libro tercero, en el que Vegecio incluye las Regulae bellorum generales (III, 26), que alcanzaron enorme difusión en la Edad Media:

\section{A. de San Cristóbal}

$(-I I-18$, fol. $96 v-97 r) \quad)$

En todas las batallas tal es la condiçion que aquellos que a ti aprouechan enpeçe al aduersario e lo que a el ayuda sienpre a ti estorua, por eso nunca deuemos fazer cosa segund su voluntad del, mas siempre deuemos fazer lo que judgamos a nos ser prouechoso, onde contra ti mesmo comienças a ser sy lo rremedias en lo que el fizo por sy, otrosy qualquier cosa que tu tenprares para tu parte contra el sera si la el quisiere arremediar. El que mas velare en el canpo e el que mas trabajare en vsar los caualleros en armas menos peligroso soferira en la batalla.

Nunca es de leuar cauallero en el haz que primero non ayas prouado.
Libro de la guerra

(ed. Lucas de Torre, p. 530-531)

La condicion de las batallas es que aquellos que a ti aprouechan dapñan al adversario, e lo que a el ayuda, a ti estorua; por eso non deuemos fazer cosa segun su voluntat.

Iten: el que mas velare e mas trabajare en el campo e usare sus caualleros en las armas menos peligro auera en la batalla: ca non es de leuar cauallero en la batalla que primero non ayas prouado. 
Mejor es domar el enemigo con mengua e con sobrevientas o rrebates o con espanto que con pelea en lo que la fortuna puede auer mayor poder.

Non ha mejores consejos que estos quel aduersario non lo sepa ante que lo fagas.

En la batalla mas suele adobar la ocasyon quel poder nin la fuerça.

En rresçebir los enemigos sy[n] con fe vienen, grand fuyzia es ca mas quebranta al aduersario los que se pasan del e lo dexan que la matança. Mejor es guardar muchos defendimientos detras de la hueste que derramar en largo la caualleria. Mala es de vençer el que verdaderamente puede judgar del su poder e del su aduersario.

Mas ayunta la fuerça e el saber que la muchedumbre.

Muchas vezes ayuda mas el lugar que el poder.

La natura pocos varones cria fuertes, la buena enseñança muchos faze ardidos.

La hueste con el trabajo aprouecha e con el vagár se envegeçe[n].
Mejor es domar al enemigo con sobreuientas e rebatos e espantos que con pelea publica, en la qual la fortuna puede auer mayor poder que la virtud del tu poder, non ha mejores consejos quel aduersario non saber lo que tu quieres fazer.

En la batalla mas suele ayudar la mañana que poder nin fuerça.

En reçebir los enemigos sy con fe se vyenen a ti, gran fiuza es.

Ca mucho quebranta al aduersario los que se parten del o lo dexan; mejor es guardar mucho defendimiento detrás de la haz, que derramar en largo la caualleria.

Malo es de vençer el que verdaderamente judga el su poder e el de los enemigos.

Mas ayuda la fuerça e el saber que la muchedumbre.

Muchas vezes ayuda mas el lugar que el poder.

La natura pocos varones cria fuertes, mas la buena enseñança a muchos faze ardidos.

La hueste con el trabajo cresçe e con el vagar se mengua... 
El texto de Vegecio de las Regulae bellorum generales (III, 26) correspondiente a estas dos versiones dice así:

In omnibus proeliis expeditionis condicio talis est, ut quod tibi prodest aduersarium noceat, quod illum adiunat tibi semper officiat. Numquam ergo ad illius arbitrium aliquid facere uel dissimulare debemus, sed id solum agere quod nobis utile iudicamus. Contra te enim esse incipit, si imiteris quod fecit ille pro se, et rursum quicquid pro tua parte temptaueris contra illum erit, si uoluerit imitari.

In bello qui plus in agrariis uigilauerit, plus in exercendo milite laborauerit, minus periculum sustinebit.

Numquan in acie producendus est cuius antea experimenta non ceperis.

Aut inopia aut superuentibus aut terrore melius est bostem domare quam proelio, in quo amplius solet fortuna potestatis baberere quam uirtus.

Nulla consilia meliora sunt nisi illa quae ignorauerit aduersarius antequam facias.

Occasio in bello amplius solet iuuare quam uirtus.

In sollicitandis suscipiendisque hostibus, si cum fide ueniant, magna fiducia est, quia aduersarium amplius frangunt transfugae quam perempti.

Melius est post aciem plura seruare praesidia quam latius militem spargere.

Difficile uincitur qui uere potest de suis et de aduersarii copiis indicare.

Amplius iunat uirtus quam multitudo.

Amplius prodest locus saepe quam uirtus.

Paucos uiros fortes natura procreat, bona institutio plures reddit industria.

Exercitus labore proficit, otio consenescit. 
El Libro de la guerra se inserta, pues, con toda claridad en la tradición de la obra de Alfonso de San Cristóbal. Y su importancia en la constitución del texto original de la tradución del teólogo dependerá de si el códice del que depende todavía existe o no. En caso negativo el Libro de la guerra podría tener un gran valor, a pesar de sus simplificaciones y manipulaciones, cuando se aborde la edición crítica de la traducción de Vegecio realizada por Alfonso de San Cristóbal.

3. Pasamos así a ocuparnos de otro interesantísimo texto castellano del Epitoma rei militaris de Vegecio, apenas conocido, si se exceptúan las brevísimas referencias a él de N.G. Round (41) y de K.A. Blüher (42). Figura en varios manuscritos, a los que nos referiremos más adelante, al final de las obras de Séneca traducidas directamente del original latino en el siglo XV por Alfonso de Cartagena (43) y es titulado de distintas maneras, bien como Tratado de la querra que fizo Séneca, o como Dichos de Séneca en el acto de cauallería, Dichos de Séneca en el fecho de la caualleria, Tratado de Séneca de la caualleria, etc.

(41) "Las traducciones medievales catalanas y castellanas de las tragedias de Séneca», AEM (1974-1979), 187-227; p. 187, n.1: "El tractado de Seneca de la caualleria, en el ms. de Madrid B.N. 17.083, fols. $111 \mathrm{v}-116 \mathrm{v}$ es de hecho una versión de sentencias escogidas de la obra de Vegecio, De Re militarin.

Èn realidad la referencia del manuscrito está equivocada, pues no es 17.083 sino 17803.

(42) Séneca en España. Investigación sobre la recepción de Séneca en España desde el siglo XIII basta el siglo XVII. (Versión española de J. Conde), Madrid 1983, p. 141: "En varios códices se encuentra además, bajo el título de Dichos de Séneca en el fecbo de la caualleria (o también Tratado de la guerra) una traducción de trozos tomados del Epitoma rei militaris de Flavio Vegecio. Es dudoso que esta traducción sea de Alonso de Cartagena».

(43) Sobre Alfonso de Cartagena siguen siendo de indispensable consulta los libros siguientes: M. Martínez Añibarro y Rives, Intento de un Diccionario Biográfico y Bibliográfico de los Autores de la Provincia de Burgos, Madrid 1889, pp. 88-115; R.P. Luciano Serrano, Los conversos D. Pablo de Santa Maria y D. Alfonso de Cartagena, Madrid, 1942, pp. 119-313; F. Cantera Burgos, Alvar Garcia de Santa Maria. Historia de Juderia de Burgos y de sus conversos más egregios, Madrid, 1952, pp. 416-464. 
Como alguno de estos títulos nos indica, se trata de dichos, sentencias o consejos generales tomados de los tres primeros libros de la obra de Vegecio y traducidos al castellano.

Este resumen, extracto, compendio o abreviación de Vegecio, que es atribuido a Séneca, plantea diversas cuestiones que se relacionan con el modelo latino utilizado, la razón de su inclusión entre las obras de Séneca y finalmente si ha sido traducido o no por Alfonso de Cartagena.

Ya nos hemos referido a uno de los extractos de Vegecio que con los nombres de Cicerón, Catón y Modesto fue conocido en toda Europa. Además de este compendio, quizás el más famoso, existieron otros muchos más, todos ellos anónimos, que llevan en los códices los nombres de Vegetii Flavii Renati dicta et flores de re militari en el ms. 7233 de la Biblioteca Nacional de París, Dicta et flores verborum $V$ egetii Flavii Renati de re militari en el ms. F. 5.22 de la Bodleian Library de Oxford etc. etc.

Y estos breves resúmenes que recogían máximas de tipo general sobre la guerra debieron tener una amplia difusión porque en ellos se resumía lo esencial de la obra vegeciana.

Sobre un modelo latino muy parecido al que sirvió de base a la traducción castellana se tradujo al francés medieval el compendio conocido con el nombre de "Aucuns notables extraitz du livre de Vegece», recintemente editado por Leena Löfstedt (44). Una comparación

(44) "Aucuns notables extraitz du livre de Vegece», en Neuphilologische Mitteilungen, LXXXIII, 1982, 297-312. De esta autora es también el importante trabajo, "Végece au Moyen Âge: motifs et modifications des traducteurs et des copistes», en Homenaje a A. Galmés de Fuentes, Madrid 1985, 493-499, y la edición crítica de la traducción de Jean de Meun: Li Abregemenz noble bomme Vegece Flave René des Establissemenz apartenaz a chavaliere, traduction par Jean de Meun, de Flavii Vegetii Renati viri ilustris Epitoma Institutorum Rei Militaris, Helsinki 1977. 
rápida entre el texto francés y castellano nos hace ver que los dos son reúmenes de los tres primeros libros y que no debe ser casualidad la coincidencia en muchos de los dichos alli incluidos; así por ejemplo:

(Veg. I, 1) La science des armes nourit la hardiesse de combatre. Nul ne resoigne a faire ce qu'il scet qu'il a bien apris. E en une bataille un petit nombre de gens bien exercités avroit plus prestement la victoire que une multitude rude et mal aprise qui n'est bonne que a soy faire tuer= Saber pelear quiere osadia, el qual saber se llama sçiençia de la republica. Ninguno no ha miedo de fazer aquello que confia aver bien aprendido. En las tablas los exerçitados dellas avnque sean pocos aparejados estan de aver vitoria. La muchedumbre ruda e non enseñada dispuesta es sienpre a muerte.

(Veg. I,9) Souventoffoiz on a ven ost soustenir grant peril des ennemis par ce qu'il estoit divisé en soy mesmes et desordonné= La hueste departida e desordenada sienpre reçibe muy gran peligro de los enemigos, etc. etc.

Admitiendo, pues, un resumen latino de Vegecio como fuente de nuestro texto, es realmente sencillo explicar por qué razón se atribuye a Séneca. En efecto, conservamos manuscritos en los que extractos de Vegecio figuran junto con otros de Séneca y otros en que aparecen al final de las obras del filósofo español, como en el ms. 205 de la Stiftsbibliothek de Rein. El paso está dado para que en copias sucesivas se atribuya a Séneca todo el contenido del manuscrito.

La atribución a Séneca de todo tipo de proverbios, sentencias, incluso de origen árabe, es un hecho constatado y sobre el que no es necesario insistir aquí.

Pensamos, pues, que Alfonso de Cartagena, cuando se dispuso a traducir a Séneca, tuvo delante un códice que incluía, además de las 
obras de este autor, proverbia, flores o dicta de otros autores y en particular de Vegecio y de Quinto Curcio (45).

Sostenemos que Alfonso de Cartagena es el traductor de los $\mathrm{Di}$ chos de Séneca apoyándonos en varios hechos. En primer lugar porque éstos aparecen en el grupo de códices, sobre todo T-III-4 de El Escorial, considerado por O. Tudorica Impey (46) como el más completo y fidedigno. En segundo lugar porque el obispo de Burgos, en una obra cuya autoría nadie pone en duda como es la «Respuesta a la qüestion fecha por el magnifico señor Marqués de Santillana», incluye, sin citarlo, referencias de Vegecio que él conoce precisamente por haber traducido un compendio de él.

En efecto, el Marqués de Santillana acababa de leer el De re militari seu de militia de Leonardo Bruni de Arezzo (47), pero en él no había encontrado una exposición lo suficientemente amplia sobre el juramento de los caballeros y es por lo que se dirige al obispo de Burgos «al qual yo ruego, pido e demando soluçion e declaraçion desta jura e sagramento" (48).

(45) G.L. Boarino, «Los Dichos de Quinto Curçio. Traducción atribuida a D. Alfonso de Cartagenam, B. Hi. LXX, 1968, 431-436, sostiene que Alfonso de Cartagena es el traductor de estos Dichos. "Puede ser, dice Boarino, que la razón principal por la que emprendió la traducción fuera la de tener referencias disponibles para ser incluidas en futuras obras didácticas, o, por otro lado, que tengamos nada más que un interés personal en el género paremiológico sin que se relacione con cualquier propósito literario didácticon.

(46) "Alfonso de Cartagena, traductor de Séneca y precursor del humanismo español», en Prohemio, III, 3, 1972, 473-494; 475.

(47) El título que aparece en el códice Ambrosiano H. 37 Sup. es éste: Leonardi Aretini De re militari seu de militia.

(48) La Question del Marqués de Santillana y la respuesta de Alfonso de Cartagena fue editada por J. Amador de los Ríos, Obras de Don Iñigo López de Mendoza, Marqués de Santillana, Madrid 1852, 487-503; M. Penna, Prosistas Castellanos del siglo XV, I, Madrid 1959, 235-245; y más recientemente, en magnifica edición crítica, por A. Gómez Moreno, "La Qüestion del Marqués de Santillana a Don Alfonso de Cartagena», en El Crotalón, 2, $1985,335-363$. Citamos por esta última. 
En la contestación, Alfonso de Cartagena le comunica que no ha leído la obra de Leonardo Bruni pero tratará de satisfacer su curiosidad, por lo que indaga sobre el significado de miles y sobre las distintas interpretaciones dadas al juramento que prestaba.

Cuando entra de lleno en el tema del juramento dice estas palabras: «Por ende, otros algunos que católicos fueron e deste juramento fazen mençión vsan destas palabras, diziendo ansí: "Jurarán los caualleros por Dios e por Nuestro Señor Ihesu Xristo e por el Espiritu Santo e por la magestad del prínçipe, la qual segunt Dios deue ser amada por el linaje humanal, que farán esforçadamente todo lo que el prinçipe les mandare, ca aquél que tiene justo prinçipado déuesele aver fiel deuoçion e fazer diligente seruiçio, commo a Dios si fuese presente; e que nunca partirán de la hueste nin refusarán la muerte por la república, en cuya guerra andan».

Pues bien, este texto, clave en la contestación del obispo de Burgos, está tomando de Vegecio (II, 5): «...milites scripti... iurare solent; et ideo militiae sacramenta dicuntur. Iurant autem per Deum et per Christum et per Spiritum sanctum et per maiestatem imperatoris, quae secundum Deum generi bumano diligenda est et colenda. Nam imperator cum Augusti nomen accepit, tamquam praesenti et corporali Deo fidelis est praestanda deuotio, impendendus peruigil famulatus. Deo enim uel priuatus uel militans seruit, cun fideliter eum diligit qui Deo rernat auctore. Iurant atem milites amnia se strenue facturos, que praeceperit imperator, nunquam deserturos militiam nec mortem recusaturos pro romana republica.

En los Dichos no es traducido el capítulo, sino partes de él: "Quando los caualleros eran escriptos en las matriculas solian jurar e por esto eran llamados sacramento de caualleria. Los tales caualleros juran por dios e por la magestad del enperador, la qual segund dios el linaje vmanal deuen mantener e onrrar. Por el enperador quando es coronado asi como a dios presente deue ser fecha fiel deuoçion. El cauallero o otro qualquier que fielmente ama al enperador sirue a dios e esto por quanto el enperador regna por dios». 
La semejanza entre la respuesta de Alfonso de Cartagena y los $D i$ chos está fuera de toda duda y la impresión es que ha sido el obispo de Burgos el autor de los dos.

Los manuscritos en los que se contiene este breve resumen castellano de Vegecio y que han sido colacionados y estudiados (49), por nosotros, son:

1) $S=$ ms. T-III-4 de la Biblioteca de El Escorial (50) del siglo XV, fols. 213r-225r. Tiene este título: «Aqui comiença el tratado de la guerra que fizo Seneca».

2) $T=$ ms. T-III-7 de la Biblioteca de El Escorial (51) del siglo XV, fols. 234r-242r. Comienza así: "Dichos de Seneca en el acto de la caualleria».

3) $M=$ ms.8188 de la Biblioteca Nacional de Madrid, del siglo XV, fols. 214v-222v. Posee este título: «Dichos de Seneca en el fecho de la caualleria».

4) $\quad N=$ ms. 17.803 de la Bibliotea Nacional de Madrid del siglo XV, fols. 111v-116v. Se titula: «Aqui comiença el tractado de Seneca de la caualleria».

5) $V=$ ms. 8830 de la Biblioteca Nacional de Madrid del siglo $\mathrm{XV}$, fols. CCCCXVIv-CCCCXXVIv. Lleva este título: "Aqui comiençan algunos dichos de Seneca en el fecho de la caualleria de rroma».

(49) Diversas dificultades nos han impedido tener en cuenta el ms. 38 de la Biblioteca Menéndez Pelayo de Santander y el ms. II-318 de la Bibioteca Universitaria de Salamanca.

(50) Para la descripción de este códice, cf. P. Fr. Julián Zarco Cuevas, Catálogo de manuscritos castellanos de la Real Bibioteca de El Escorial, Madrid 1926, t. II, 391-393.

(51) Cf. J. Zarco, op. cit., 397-399. 
La constitución del texto se basa, pues, en estos cinco códices, que se dejan agrupar fácilmente en dos familias, una representada por $S$ y otra por $T M N V$.

Para saber cuál de estas dos familias nos ha transmitido la lección auténtica, hemos identificado previamente en Vegecio los capítulos o mejor trozos de capítulos a los que corresponden los Dichos, que serán también editados.

De acuerdo con esto proponemos el siguiente stemma:

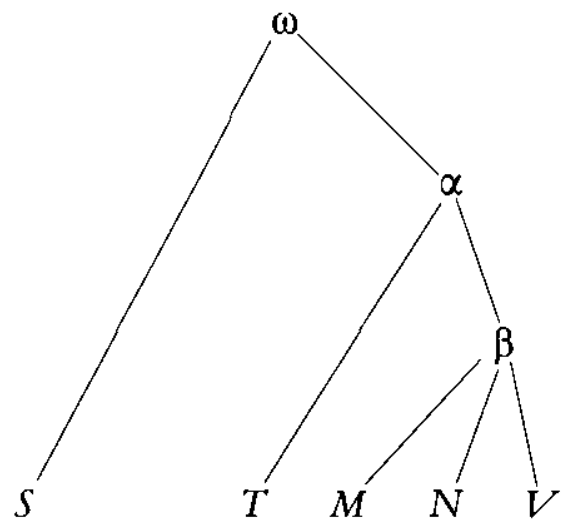

Breve explicación, en sus grandes ramas, del stemma propuesto:

1) $S$ por una parte y $T M N V(=\mathrm{A})$ por otra son independientes entre si:

a) Errores separativos de $T M N V$ respecto a $S$ :

3. breuedat $S$ (= breuitas $V e g$.$) : benignidat T$ benignidad $M V N$ 
61. de guerra e S: om. TMNV

64. todos $S$ (= omnes $V$ eg. $):$ tomados $T M N V$

69. comprehendidas $S(=$ comprehendi $V$ eg. $)$ : aprendidas TMNV

77. acabdilla $S$ ( = praeerat $V$ eg. $): o m . T M N V$

85. interese $S$ ( = utilitatibus $V$ eg.) : om. $T M N V$

130. dañe $S$ ( = noceat $V$ eg. $):$ deuen $T M N V$

b) Errores separativos de $S$ respecto a $T M N V$

8. sçiençia $T M N V$ (= scientia $V$ eg.) : justiçia $S$

16. septentrional $T M N V$ ( = septentrionales $V$ eg. $): o m . S$

48. a las feridas $T M N V$ ( = ad vulnera $V e g$.$) : om.S$

71. presente en cuerpo TMNV ( = praesenti et corporali $V$ eg.) : presente $S$

88. instinto $T M N V$ ( = instictu $V$ eg. $)$ : mandamiento $S$

91. ferir $T M N V$ ( = feriendi $V$ eg.): estar $S$

141. siempre tientan $T M N V$ ( = semper adtemptant Veg.) : non temen $S$.

Así pues, parece claro que el arquetipo $\omega$ se conseguirá aunando las dos ramas de la tradición aqui establecidas. No obstante consideramos que $S$ en conjunto es el códice más completo (52) y a él nos atenemos en los casos de variantes no significativas, sobre todo las de tipo gráfico.

Respecto al título, hemos elegido el de la familia $\alpha$, y concretamente el del ms. $T$, por responder mejor a la materia tratada.

(52) El ordenamiento correcto de los Dichos es el que traen TMNV y es el que seguimos. El códice $S$, por trastueque de algún folio en la encuadernación, los presenta alterados. 


\section{DICHOS DE SENECA EN EL ACTO DE LA CAVALLERIA}

1.-Tu me cree, los romanos todas las gentes aver vençido por el vso de las armas.

2.-E solo por esto los pocos romanos prevalesçieron contra la muchedumbre de los galicos.

3.-E por esto la breuedat de los romanos pudo contra la porfia de los germanos.

4.-E asi mesmo contra los españoles non solo por numero mas por fuerça corporal ser antepuestos a los romanos magnifiesta cosa es.

5.-Et asi mesmo vençieron a los afros a los ingenios e riquezas de los quales sienpre los romanos non se pudieron ygualar.

6.-Asi mesmo a los griegos por la prudençia e artes de los quales los romanos eran vençidos.

7.-Los romanos preualesçieron por la prudençia muy diligente de los sus tirones.
1.-Nulla enim alia re uidemus populum Romanum orbem subegisse terrarum nisi armorum exercitio (I,I, p.13, 6-7)

2.-Quid enim adversus Gallorum multitudinem paucitas romana ualuisset? (I,I, p. 13, 7-8)

3.-Quid aduersus Germanorum proceritatem breuitas potuisset audere? (I,I, p. 13, 9-10)

4.-Hispanos quidem non tantum numero sed et uiribus corporum nostris praestitisse manifestum est. (I,I, p. 13, 10-12)

5.-Afrorum dolis atque diuitiis semper impares fuimus (I,I, $\mathrm{p}$. $13,12-13)$

6.-Graecorum artibus prudentiaque nos uinci nemo dubitauit (I,I, p. 14, 13)

7.-Sed adversus omnia profuit tironem sollerter eligere... $(I, I, P$. 14, 1-2) 
8.-Saber pelear quiere osadia, el qual saber se llama sçiençia de la republica.

9.-Ninguno no ha miedo de fazer aquello que confia aver bien aprendido.

10.-En las batallas los excerçitados dellas avnque sean pocos aparejados estan de aver vitoria.

11.-La muchedumbre ruda e non enseñada dispuesta es sienpre a muerte.

12.- Cosa manifiesta es en todos los lugares ser nasçidos omes couardes e otros muy nobles.

13.-Pero en las batallas ha ventaja vna gente de otra.

14.-Algunas partidas segund el sitio çelestial no solamente para fuerça corporal mas avn para la fuerça de los coraçones mucho valen en las batallas.

15.-Non son de escoger para las batallas de las naçiones vezinas del sol las quales son desecadas por la mucha calor e por la poca sangre non tienen fiuzia ni fyrmeza de pelear avnque de otra manera sean sabidores.

16.-Nin son de escoger de la parte septentrional por que arredrados del sol son, e por la mucha sangre no saben consejar e son muy aparejados a la pelea.

17.-Pues que asi es de la parte mas tenplada son de tomar los tyrones a los quales no fallesçe copia de sangre para menospreçiar las feridas nin en la muerte les puede menguar la prudençia.
8.-Scientia enim rei bellicae dimicandi nutrit audaciam. (I, I, p. $14,6-7$ )

9.-Nemo facere metuit quod se bene didicisse confidit (I,I P. 14. 7-8)

10.-Etenim in certamine bellorum excercitata paucitas ad uictoriam promptior est. (I,I, p.14, 8-9)

11.-Rudis et indocta multitudo exposita semper ad caedem. (I,I, p. 14, 9-10)

12.-Constat quidem in omnibus locis et ignauos et strenuos nasci (I,II, p. 15, 1-2)

13.-Sed tamen et gens gentem praecedit in bello (I, II, p. 15, 2)

14.-Plaga caeli ad robur non tantum corporum sed etiam animorum plurimum ualet (I, II, p. 15, 3-4)

15.-Omnes nationes, quae uicinae sunt soli, nimio calore siccatas, amplius quidem sapere, sed $\mathrm{mi}$ nus habere sanguinis dicunt ac propterea constantiam ac fiduciam comminus non habere pugnandi (I, II, p. 15, 5-10)

16.-Contra septentrionales populi, remoti a solis ardoribus, inconsultiores quidem, sed tamen largo sanguine redundantes, sunt ad bella promptissimi (I, II, p. $15,10-12)$

17.-Tirones igitur de temperatioribus legendi sunt plagis, quibus et copia sanguinis suppetat ad uulnerum mortisque contemptum et non possit deesse prudentia (I, II, p. 15, 13; p. 16, 1-2) 
18.-La prudençia guarda el modo en los castillos e non menos aprouecha el consejo en las batallas.

19.-Aquel pueblo rustico es mas abto para las armas que es criado so el graue trabajo paçiente del sol no curante de sonbra e non sabidor de los baños e ynorante de las deletaçiones e de coraçon synple, contento con poca cosa e de mienbros duros para sobreleuar todos los males, al qual leuar el fierro e fazer las cauas e soportar todos trabajos es de costunbre.

20.-Pero a las vezes la nesçesidat demanda a los çibdadanos ser apremiados para tomar armas.

21.-Nesçesaria mente menos teme la muerte aquel que en la vida menos sopo de las delectaçiones.

22.-Non solo mas ligera mente son aprendidas las cosas que ome aprende en la moçedad mas avn mas prouechoso es.

23.-La alegria militar, el saltar e el correr ante es de tentar que el cuerpo por hedat se faga grueso.

24.-La ligereza tomada por exerçiçio muy noble faze al guerrero.

25.-Mejor es al mançebo exerçitado ser causa de non aver aun hedat para pelear que non que se duela de aquella ser pasada. 18.-...prudentia, quae et modestiam seruat in castris et non parum prodest in dimicatione consiliis. (l, II, p. 16, 2-4)

19.-De qua parte numquam credo potuisse dubitari aptiorem armis rusticam plebem, quae sub diuo et in labore nutritur, solis patiens, umbrae neglegens, balnearun nescia, deliciarum ignara, simplicis animi paruo contenta, duratis ad omnem laborum tolerantiam membris cui gestare ferrum, fossam ducere onus ferre consuetudo de rure est. (I, III, p. 16, 7-13)

20.-Interdum tamen necessitas exigit etiam urbanos ad arma compelli (I, III, p. 16, 13-p. 17, 1)

21.-Nescio quomodo enim minus mortem timet qui minus deliciarum nouit in uita. (I, III, p. 18, 6-7)

22.-Non enim tantum celerius sed etiam perfectius imbuuntur quae discuntur a pueris (I, IV, p. 18 , 12- 19, 1)

23.-Deinde militaris alacritas, saltus et cursus ante temptandus est, quam corpus aetate pigrescat. (I, IV, p. 19, 1-3)

24.-Velocitas enim est quae percepto exercitio strenuum efficit bellatorem. (I, IV, p. 19, 3-4)

25.-Melius enim est, ut exercitatus iuuenis causetur aetatem nondum aduenisse pugnandi, quam doleat praeterisse. (I, IV, p. 19, 7-9) 
26.-La nesçesidat manda que tanto se demande de la statura quanto de la fuerça.

27.-La virtud por muchas señales se declara.

28.-Es de saber que el mançebo deputado para la obra de la guerra tenga ojos veladores, çeruiz derecha, pecho ancho, onbros carnosos, dedos valientes, los braços luengos, pequeño vientre, delgadas piernas no por demasiada carne cargadas, mas ayuntadas con dureza de neruios.

29.-Mas prouechosa cosa es los caualleros ser fuertes que grandes.

30.-Esto es aquello que la salud de toda la republica consiste que los tirones sean escogidos no tan sola mente por los cuerpos, mas muy prestos por los coraçones.

31.-Aquestos son fundamento del noble reyno romano.

32.-E si aver se pueden deuen sobrepujar en costumbres.

33.-Esto por que la onestad faze al cauallero pertenesçiente.

34.-De los grandes varones e con gran diligençia deuen ser escogidos los mas mançebos pertenesçientes.

35.-Muchos maguer que sean vistos omes de pro, pero por la espiriençia se prueuan ser non dignos.
26.-Si ergo necessitas exigit, non tam staturae rationem conuenit habere quam uirium. ( $\mathrm{I}, \mathrm{V}, \mathrm{p}$. $21,5-7$ )

27.-Uirtus multis declaratur indiciis. (I, VI, p. 22, 3-4)

28.-Sit ergo adulescens Martio operi deputandus uigilantibus oculis, erecta ceruice, lato pectore, humeris musculosis, ualentibus brachiis, digitis longioribus, uentre modicus, exilior clunibus, suris et pedibus non superflua carne distentis sed neruorum duritia collectis. (I, VI, p. $22,10-11$, p. $23,1-3$ )

29.-Utilius est enim fortes milites esse quam grandes. (I, VI, p. 23, 5-6)

30. -Et hoc est in quo totius rei publicae salus uertitur, ut tirones non tantum corporibus sed etiam animis praestantissimi deligantur. (I, VII, p. 24, 3-5)

31.-Uires regni et romani nominis fundamentum in prima dilectus examinatione consistunt. (I, VII, p. 24, 5-7)

32.-Si copia suppetat, et moribus debet excellere. (I, VII, p. 24, 11-12)

33.-Honestas enim idoneum militem reddit (I, VII, p. 25,1 )

34.-A magnis ergo uiris magnaque diligentia idoneos eligi conuenit iuniores. (I, VII, p. 25, 11-12)

35.-Plerique enim, quamuis non improbabiles uideantur in specie, tamen experimentis comprobantur indigni. (I, VIII, p. 26, 7-9) 
36.-En toda batalla no tanto aprouecha la muchedunbre como la virtud.

37.-¿Quien fallaras que pueda ensenaar lo que el no aprendio?

38.-La hueste departida e desordenada sienpre reçibe muy gran peligro de los enemigos.

39.-Los mas mançebos mayor mente son de acostumbrar en el correr por que mayor enpellon den en los enemigos.

40.-Non tomo para $\mathrm{mi}$ abtoridat, mas las cosas de otros, que derramadas estan, escriuo.

41.-Muchas vezes por lluuias arrebatadas suelen creçer los rios; por ende vsar nadar muy prouechoso es por que como la nesçesidat acaesçiere no venga algund daño a los que lo non saben.

42.-No ay cosa mas firme ni mas bien aventurada nin mas loable en la republica que aver abundançia de caualleros asaz ensenados de guerra.

43.-El abastamiento de las vestiduras ni del oro ni de la plata ni de las piedras preçiosas no aba$x a$ al enemigo que nos faga reuerençia, mas solo lo sojudga el temor de las armas.
36.-In omni enim conflictu non tam prodest multitudo quam uirtus. (I, VIII, p. 26, 10-12)

37.-Quem inuenias qui docere possit quod ipse non didicit? (I, VIII, p. $27,2-3$ )

38.-Periculum enim ab hostibus semper grauissimum sustinet diuisus et inordinatus exercitus. (I, IX, p. 29, 3-4)

39.-Sed et cursu praecipue assuefaciendi sunt iuniores, ut maiore impetu in hostem procurrant. (I, IX, p. 29, 9-10)

40.-De historiis ergo uel libris nobis antiqua consuetudo repeten da est. Sed illi res gestas et euentus tantum scripsere bellorum, ista, quae nunc quaerimus, tanquam nota linquentes? (I, VIII, p. 27)

41.-Saepe repentinis imbribus uel niuibus solent exundare torrentes, et ignorantia non solum ab hoste, sed etiam ab ipsis aquis discrimen incurrit. (I, X, p. 31, 8-11)

42.-Nihil enim neque firmius neque laudabilius neque felicius est republica, in qua abundant milites eruditi. (I, XIII, p. 37, 5-7)

43.-Non enim uestium nitor uel auri argenti gemmarumque copiae hostes aut ad reuerentiam nostram aut ad gratiam inclinant, sed solo terrore subiguntur armorum. (I, XIII, p. 37, 7-10) 
44. - $\mathrm{Si}$ alguna cosa es errada puedese despues emendar, pero los yerros de las batallas no reçiben emienda, como la pena en ese punto sigue al yerro.

45.-Luego peresçen aquellos que couarde mente o syn saber pelean, o dados a fuyr no pueden ser para adelante yguales de los vençedores.

46.-La fuerça cresçe a los braços por el vso e el saber tyrar se gana por sabiduria e vso.

47.-No ay cosa alguna quel pensamiento contynuo no faga ligera.

48.-No entienden pelear mas fuyr aquellos que desanparados e desarmados se ponen en la batalla a las feridas.

49.-Lo que continua mente se vsa no es trabajoso avnque sea cargoso.

50.-Nesçesario es ser osado para pelear; el que armado lieua la cabeça e el cuerpo non ha temor de las feridas.

51.-Sy el real fuere bien ordenado los caualleros que dentro estouieren avnque sean çercados de los enemigos pueden estar seguros de dia e de noche como sy estouiesen en villa çercada.

52.-Ninguno no llega al fyn de su muerte si no quando fallesçe la voluntad de proseguir a su enemigo. 44.-..si quid erratum est, potest postmodum corrigi; proeliorum delicta emendationem non recipiunt, cum poena statim sequatur errorem. (I, XIII, p. 37, 11-13)

45.-Nam aut confestim pereunt qui ignaue imperiteque pugnauerint aut in fugam uersi uictoribus ultra pares esse non audent. (I, XIII, p. 38, 1-3)

46.-Eo enim exercitio et lacertis robur accrescit et iaculandi peritia atque usus adquiritur. (I, XIV, p. $39,1-2)$

47.-Nihil enim est, quod non assidua meditatio facillimum reddat (I, XIX, p. 46, 1-2)

48.-Ita fit, ut non de pugna sed de fuga cogitent qui in acie nudi exponuntur ad uulnera. (I, XX, p. $48,4-6$ )

49.-Ceterum cotidianus usus non laborat, etiam si onerosa gestauerit. (I, XX, p. 49, 1-2)

50.-Necesse est enim, ut dimicandi acriorem sumat audaciam qui munito capite uel pectore non timet uulnus (I, XX, p. 53, 2-4)

51. $-\mathrm{Si}$ recte constituta sunt castra, ita intra uallum securi milites dies noctesque peragunt, etiam si hostis obsideat, quasi muratam ciuitatem uideantur secum ubique portare. (I, XXI, p. 53, 8-11)

52.-Nec prius moriundi finis fit, quam hostibus uoluntas defuerit persequendi. (I, XXI, p. 54, 8-10) 
53.-La cura del excerçiçio de la caualleria entonçe se conosçe ser en lo postrimero oluidada quando primera mente se faze con pereza e despues se disimula.

54.-Los mançebos sienpre deuen ser escogidos e trabajados.

55.-Menos cuesta enseñar a los suyos en las armas que a los agenos dar sueldo.

56.-En la caualleria el fecho es prueua del arte.

57.-De los libros avemos las cosas antiguas.

58.-De buen prinçipe buen cauallero el qual con fazañas nueuas sobrepuja la antyguedat.

59.-La verguença muchas vezes faze pelear.

60.-La desobediençia llena es de peligro e de daño de la cosa sacra la qual es la caualleria.

61.-En latyn es llamada la hueste exerçito, la qual se tomo de otra palabra de latyn dicha de exerçiçio que quiere dezir vso e por esto dize aqui Seneca quel exerçiçio quiere dezir vso e trabajo de guerra e de caualleria, e por que nonbra esta palabra hueste no oluidemos el trabajo e vso de las armas donde la hueste tomo nonbre.

62.-Nesçesario es los que desacuerdan ante de la pelea mas tarde venir a vitoria.
53.-Ita cura excercitii militaris primo neglegentius agi, postea dissimulari, ad postremum olim in obliuionem perducta cognoscitur. (I, XXVIII, p. 66, 3-6)

54.-Semper ergo legendi et exercendi sunt iuniores. (I, XXVIII, p. $67,3-4)$

55.-Vilius enim constat erudire armis suos quam alienos mercede conducere. (I, XXVIII, p. 67, 4-5)

56.-Siquidem indubitata approbatio artis sit rerum semper effectus. (II, Prolog. p. 72, 3-4)

57.-Ex libris antiqua desiderat. (II, Prolog. p. 72, 6-7)

58.-Cum ipsam antiquitatem factis recentibus antecedat. (II, Prolog. p. 72)

59.-Certauit saepius deuotio cum pudore. (II, Prolog. p. 73, 1)

60.-Rursus tanti imperatoris non oboedire preceptis plenum sacrilegii uidebatur atque periculi. (II, Prólog. p. 73, 5-7)

61.-Exercitus ex re ipsa atque opere excercitii nomen accepit, ut ei numquam liceret obliuisci quod uocabatur. (II, I, p. 76, 4-6)

62.-Necesse est autem tardius ad uictoriam peruenire qui discrepant. (II, II, p. 78, 9-10) 
63.-Como en las faziendas aproueche mucho todos los caualleros ser regidos por señal de vn mandamiento, non pueden egual men. te conplir lo que les fuere mandado aquellos que en ante no fueron en vno.

64.-Como la cobdiçia ocupe los galardones de la virtud, son fechos por gracia caualleros los que por trabajo se solian fazer.

65.-Aquellas cosas son eternas las quales por prouecho de la republica son escriptas.

66.-Los mandamientos e hordenanças de los mayores estrecha e fiel mente deuen ser acatados.

67.-Tanto cuesta la hueste mal ordenada como la bien ordenada.

68.-Quando la declaraçion paresçe ser mas escura o mas synple, non se deue contar al actor mas a la dificultad de la cosa en si mesma.

69.-Para que las cosas puedan ser conprehendidas e en las memoria entendidas con coraçon atento, son muchas vezes de reueer.

70.-Quando los caualleros eran escriptos en las matriculas solian jurar e por esto eran llamados sacramento de caualleria. Los tales caualleros juran por dios e por la magestad del enperador la qual segund dios el linaje vmanal deuen mantener e onrrar.

71.-Por el enperador quando es coronado asi como a dios presente en cuerpo deue ser fecha fiel deuoçion.
63.-Denique cum in expeditionibus plurimum prosit omnes milites unius praecepti significatione conuerti, non possunt aequaliter iussa complere qui ante pariter non fuerunt. (II, II, p. 79, 1-4)

64.-Cum uirtutis praemia occuparet ambitio et per gratiam promouerentur milites, qui promoueri consueuerant per laborem. (II, III, p. 81, 1-3)

65.-Quae uero pro utilitate reipublicae scribuntur aeterna sunt. (II, III, p. 82, 8-9)

66.-Eorum instituta, horum praecepta,...strictim fideliterque signabo. (II, III, p. $83,2-3$ )

67.- $\dot{c}$ ?

68.-Quae descriptio si obscurior aut impolitior uidebitur, non mihi sed difficultati ipsius rei conuenit imputari. (II, IV, p. 84, 6-8)

69.-Attento itaque animo saepius relengenda sunt, ut memoria intelligentiaque ualeant comprehendi. (II, IV, p. 84, 8-10)

70.-Milites scripti, cum matriculis inseruntur, iurare solent; et ideo militiae sacramenta dicuntur. Iurant autem per Deum et per Christum et per Spiritum sanctum et per maiestatem imperatoris, quae secundum Deum generi humano diligenda est et colenda. (II, V, p. 85, 6 ss.)

71.-Nam imperator cum Augusti nomen accepit, tamquam praesenti et corporali Deo fidelis est praestanda deuotio. (II, V, p. $86,2-4)$ 
72.-El cauallero o otro qualquier que fiel mente ama al enperador sirue a dios e esto por quanto el enperador regna por dios.

73.-El cauallero deue ser guardador diligente e mesurado dotrinador del pueblo, a el encomendado a toda deuoçion $\mathrm{e}$ industria por continuas obras.

74.-Deue fazer la virtud de sus subditos a loor de dios.

75.-Aquello derecha mente enseñara el cauallero a los otros que con loor el fiziere.

76.-La conpania de los caualleros deue floresçer por renta, linaje, letras, fermosura e virtud.

77. -El cauallero que acabdilla tal conpaña deue ser mesurado en el saber de las armas e en la fuerça del cuerpo e en la onestad de sus costunbres.

78.-¿Quien deue ser el cauallero guerrero que por disimulaçion dexa ensuziar las armas de oryn?

79.-No sola mente los caualgadores mas avn los cauallos se deuen enseñar por contynuo trabajo.

80.-Ley es que la az de ligero non fuya ni de ligero siga.

81.-La az bien ordenada es como fortaleza bien murada.

82.-El que por salud de la republica bien trabaja e busca cosas nueuas restituye las antiguas.
72.-Deo enim uel priuatus uel militans seruit, cum fideliter eum diligit qui Deo regnat auctore. (II, V, p. 86, 4-6)

73.-Ipse autem custos, diligens, sobrius legionem sibi creditam assiduis operibus ad omnem deuotionem, ad omnem formabat industriam. (II, IX, p. 98, 6-8)

74.-Sciens ad preafecti laudem subiectorum redundare uirtutem. (II, IX, 8-9)

75.-Is post longam probatamque militiam peritissimus omnium legebatur, ut recte doceret alios quod ipse cum laude fecisset. (II, X, p. 100, 3-5)

76.-Sed prima erat miliaria, in qua censu genere litteris forma uirtute pollentes milites mittebantur. (II, XII, p. 102 4-6)

77.-Huic tribunus praeerat armorum scientia, mirtute corporis, morum honestate praecipuus. (II, XII, p. 102, 6-6)

78.-Quis credat militem bellicosum, cuius dissimultaione situ ac robigine arma foedantur? (II, XIV, p. 108)

79.-Non solum autem equites sed etiam ipsos equos assiduo labore conuenit edomari. (II, XIV, p. $108,5-6)$

80.-...legionis ius est facile nec fugere nec sequi. (II, XVII, p. 115 , 9-10)

81.-Ex his igitur apparet legionem bene institutam quasi munitissimam esse ciuitatem. (II, XVIII, p. $116,9-10$ )

82.-...ut pro salute reipublicae et noua excogitet et antiqua restituat. (II, XVIII, p. 118, 2-3) 
83.-Toda cosa paresçe ser difiçile ante de ser tentada.

84. - La diligençia fara toda cosa que quiera si la costa que para ello cunple no es denegada.

85.-Cosa no convenible paresçe al cauallero del enperador ser sostenido de vistuario e mantenimiento de la cosa publica e entender en su priuado interese.

86.-Muchos omes e mayor mente los pobres despienden quanto alcançar pueden.

87.-De aquellas cosas ha ome gran cuydado en que vee ser puesta toda su sustancia.

88.-Las azes de los romanos no sola mente fueron ordenadas por consejo mas avn por instinto diuino, las quales asi eran ordenadas quel ayuntamiento de todas las batallas paresçia ser vn cuerpo.

89.-Natural mente los de cauallo suelen desacordar de los peones.

90.-La hedat luenga nin los muchos años no fazen saber el arte del pelear.

91.-La ligereza por el vso del cuerpo se gana e eso mesmo saber ferir el enemigo delante o del se defender.

92.-Muchas vezes entre los que saben acaesçe algund error.
83.-Omne opus difficile uidetur, antequam temptes. (II, XVIII, p. $118,3-4)$

84.-Quiduis enim efficit sollertia, si competentes non denegentur expensae. (II, XVIII, p. 118, 7-8)

85.-Siquidem incongruum uideretur imperatoris militem, qui ueste et annona publica pascebatur, utilitatibus uacare priuatis. (II, XIX, p. $1207-9$ )

86.-Plerique enim homines et praecipue pauperes tantum erogant, quantum habere potuerint. (II, XX, p. 122, 1-3)

87.-More humani ingenii, ut pro illis habeat maximam curam, in quibus suam uidet positam esse substantiam. (II, XX, p. 122, 9, p. 123,1$)$

88.-Non tantum humano consilio sed etiam diuinitatis instinctu legiones a Romanis arbitror constitutas. In quibus decem cohortes ita sunt ordinatae, ut omnium unum corpus, una uideatur esse coniunctio. (II, XXI, p. 124, 3-6)

89.-...cum naturaliter equites a peditibus soleant discrepare. (II, XXI, p. $125,7-8$ )

90.-Neque enim longitudo aetatis aut annorum numerus artem bellicam tradit. (II, XXIII, p. 128, 9-10)

91.-Nam et uelocitas usu ipso adquiritur corporis et scientia feriendi hostem seque protegendi, praesertim si gladiis comminus dimicetur. (II, XXIII, p. 129, 5-7)

92.-Nec inter doctos aliquis error existit. (II, XXIII, p. 130, 3) 
93.-Syn temor fazian los caualleros en la batalla lo que trebejando avian fecho en el campo.

94.-Quando los caualleros no continuan las armas; mal vsan dellas, adexa toma los coraçones $\mathrm{e}$ cuerpos dellos se enflaqueçen.

95.-Por esto les conviene a menudo excerçitarse en tales cosas, que quando los trabajos de la guerra vengan no les sean cargosos.

96.-Esto por que continua mente vsando dello en la paz no se les faga graue en la guerra.

97.-Bien asi como el cauallero vsado en armas aesea el pelear, asi lo reçela el que non lo ha acostumbrado.

98.-Saber conviene que en la pelea mas aprouecha vso que fuerça.

99.-Sy el sabe. de las armas çesase, no avria diferençia del cauallero al labrador.

100.-Cunple al cauallero por cuyas manos ha de ser guardada la republica que diligente mente guarde e continue el saber pelear e vsar de guerra.

101.-Cada vno deue pelear por su salud e por la libertad de todos.

102.-Sentençia es de todos los sabios antiguos que las artes son en el pensamiento.

103.-El fecho de la caualleria consiste en virtud $e$ bien andança.
93.-Propterea sine trepidatione in acie faciebant quod ludentes in campo fecerant semper. (II, XXIII, p. 131, 6-8)

94.-Exerceri cogebantur in campo, ne intermissa consuetudo et animos militum debilitaret et corpora. (II, XXIII, p. 133, 1-2)

95.-Siue ergo legio siue auxilia fuerint, exerceantur assidue. (II, XXIII, p. 133, 7-8)

96.-...frequentissime conuenit, ut cotidiani laboris usus in pace difficilis non uideatur in bello. (II, XXIII, p. 133, 5-7)

97.-Nam quemadmodum bene exercitatus miles proelium cupit, ita formidat indoctus. (II, XXIII, p. $133,8-9)$

98.-Postremo sciendum est in pugna usum amplius prodesse quam uires. (II, XXIII, p. 133, 9-10)

99.-Nam si doctrina cesset armorum, nihil paganus distat a milite. (II, XX.II, p. 133, 10-11)

100.-Militem, cuius est manibus seruanda respublica, studiosius oportet scientiam dimicandi usumque rei bellicae iugibus excercitiis custodire. (II, XXIV, p. $134,5-7$ )

101.-Miles... cui pugnandum est pro salute propria et libertate communi. (II, XXIV, p. 135, 4-5)

102.-...praesertim cum antiqua sit prudensque sententia omnes artes in meditatione consistere. (II, XXIV, p. 135, 5-6)

103.-Rem militarem, quae uirtute solo uel certe felicitate creditur contineri. (III, Prolog. p. 4, 5) 
104.-Muy marauillosa mente son de loar los caualleros que aquesta arte de la caualleria quisieron aprender syn la qual las otras artes no pueden estar.

105.-El que quisiere ayuntar en vna mediania lo que esta derramado por diversos libros de los actores, conviene que non sea tan luengo que enoje nin tan breue que fallesca el conplimiento de la verdat.

106.-Quien desea paz apareje guerra.

107.-El que cobdiçia aver vitoria diligente mente enseñe a sus caualleros.

108.-Quien buenas andanças quiere, pelee por arte e non por aventura.

109.-E para esto no cure de perseguir ni sea osado de cometer a aquel que entiende que peleando le sobre pujara.

110.-La muchedumbre esta dispuesta a muchas aventuras.

111.-Nesçesario es de los muchos peresçer muchos.

112.-Los antiguos no tanto quisieron la muchedumbre de las huestes como que fuesen enseñados en armas.

113.-Muchas vezes acaesçen dolençias por calor del sol o por el cansançio del camino.
104.-O uiros summa admiratione laudandos, qui eam praecipue artem ediscere uoluerunt, sine qua aliae artes esse non possunt! (III, Prolog. p. 5, 1-2)

105.-Quae per diuersos auctores librosque dispersa, imperator inuicte, mediocritatem meam abbreuiare iussisti, ne uel fastidium nasceretur ex plurimis uel plenitudo fidei deesset in paruis. (III, Prolog. p. 5, 3-5)

106.-Igitur qui desiderat pacem, praeparet bellum (III, Prolog. p. 5, 11-12)

107.-Qui uictoriam cupit, milites inbuat diligenter. (III, Prolog. p. 5,12$)$

108.-Qui secundos optat euentus, dimicet arte, non casu. (III, Prolog. p. $5,12-13$ )

109.-Nemo prouocare, nemo audet offendere quem intellegit superiorem esse pugnaturum. (III, Prolog. p. 5, 13-14)

110.-Nam pluribus casibus subiacet amplior multitudo. (III, I, p. 6 10-11)

111.-Necesse est multos cadere de multis. (III, I, p. 7, 5)

112.-Veteres autem, qui remedia difficultatum experimentis didicerant, non tam numerosos quam eruditos armis exercitus habere uoluerunt. (III, I, p. 7, 6-7)

113.-...ne egressi tardius et calore solis et fatigatione itineris contrahant morbum. (var. morbos) (III, II, p. 9, 2-3) 
114.-No es pertenesçiente cauallero para sanidat nin para guerra el que es apremiado por el frio.

115.-La fanbre mas cruel es quel fierro.

116.-Vna es la mayor arma que en toda fazienda puedes aver, la qual es que tu seas abastado de viandas $e$ tus enemigos ayan mengua dellas.

117.-No es segura la posision de las riquezas, si por defension de armas no es guardada. En muchas vezes se dobla la nesçesidat $\mathrm{e}$ acaesçe muchas vezes que quando algund lugar es çercado mas dura la çerca de quanto es pensado.

118.-La paz que se faze infyntosa mente, asi mesmo las mercadurias fyngidas, mas daño suelen traer que las armas de los enemigos a los que los creen.

119.-Muchos se muestran ayrados por no yr a la guerra, mayor mente aquellos que biuen en reposo delicada mente.

120.-Non se espanta del ruydo de la batalla aquel que ha fuerça e se fia en arte de guerra.

121.-Los muchos no por egual voluntad vienen en desobediençia, mas antes son escandalizados por pocos malos omes queriendo los tales pecar con los muchos por la poca pena que esperan de sus maldades e de sus delictos.

122.-Cosa muy derecha es que la pena sea esecutada en los mereçedores della, por que todos ayan temor avn que pocos sean penados.
114. -Nec sanitati enim nec expeditioni idoneus miles est, qui algere conpellitur. (III, II, p. 9, 5-6)

115.-Ferro saeuior fames est. (III, III, p. 11, 3).

116.-In omni expeditione unum est et maximum telum, ut tibi sufficiat uictus, hostes frangat inopia. (III, III, p. 11, 5-6)

117.-Neque enim diuitiarum secura possessio est, nisi armorum defensione seruetur. Frequenter autem necessitas geminatur et obsidio saepe fit longior quam putaris. (III, III, p. 11, 10-p. 12, 1-2)

118.-Frequentius enim commerciorum pacisque simulatio credulis quam arma nocuerunt. (III, III, p. $13,9-10)$

119.-...cum pugnare nolit, irasci se simulat cur non ducatur ad bellum; quod hi praecipue faciunt qui in sedibus otiose delicateque uixerunt. (III, IV, p. 14, 2-4)

120.-Nemo cogitat de tumultu qui fiduciam de arte uel uiribus gerit. (III, IV, p. 15, 10)

121.-Numquam enim ad contumaciam pari consensu multitudo prorumpit, sed incitatur a paucis, qui uitiorum scelerumque inpunitatem sperant peccare cum plurimis. (III, IV, p. 16, 5-6)

122.-...rectius est more maiorum in auctores criminum uindicari, ut ad omnes metus, ad paucos poena perueniat. (III, IV, p. 16, 7-8) 
123.-Aquellos capitanes son más de loar que su hueste es enseñada de buena tenprança por vso e trabajo que non los otros cuyos caualleros son traydos a obediençia por temor o tormentos.

124.-Do quier que se trate de la salud no sea dado perdon al perezoso en ella.

125.-A las vezes los rusticos non sabidores afyrman saber muchas cosas que no saben.

126.-Muy seguro es en el fecho de la guerra no ser sabido aquello que se ha de fazer. Aquel es seguro camino de que los enemigos no sospechan la via.

127.-Esto acaesçe por que muchas vezes es tomado el que se pasa de vna parte a otra por que nunca fallesçen traydores.

128.-El cabdillo de la hueste deue aver personas muy fieles argumentados que en el andar del camino a la mano derecha e a la ysquierda siempre catem.

129.-Mas seguramente obran las espias de noche que de dia. El salto se da a los omes que andan a las vezes por la frente e por la mayor parte de las espaldas.

130.-Por que la sobrevienta de juntamiento non dañe en la hueste, son ante de avisar los caualleros que esten prestos de coraçon.
123.-Laudabiliores tamen duces sunt, quorum exercitum ad modestiam labor et usus instituit, quam illi, quórum milites ad oboedientiam suppliciorum formido conpellit. (III, IV, p. 16, 8-10)

124.-Siquidem nulla sit neglegentiae uenia, ubi de salute certatur. (III, V, p. 17, 2-3)

125.-Interdum autem imperita rusticitas plura promittit et credit se scire quae nescit. (III, VI, p. 21,9$)$

126.-...ita ducis consilium semper esset occultum. Securum iter agitur quod agendum hostes minime suspicantur. (III, VI, p. 22, 4-5)

127.-Verum, quia exploratores altrinsecus missi profectionem suspitionibus uel oculis deprehendunt et interdum transfugae proditoresque non desunt. (III, VI, p. $22,5-7)$

128.-Dux cum agmine exercitus profecturus fidelissimos argutissimos... qui loca per quae iter faciendum est, in progressu et a tergo, dextra laeuaque perlustrent.

129.-Tutius autem operantur exploratores noctibus quam diebus... Nam ambulantibus interdum quidem a fronte, sed frequentius a tergo superuentus infertur. (III, VI, p. 23, 1-5, 5-6)

130.- $\mathrm{Ne}$ uero repentinus tumultus amplius noceat, ante commonendi sunt milites, ut parati sint animo. (III, VI, p. 24, 1-2) 
131. -Las cosas proveydas no suelen ser subjetas al miedo.

132.-En los campos abiertos mas suelen pelear los caualleros que los peones.

133.-En los canpos son de poner delante los caualleros sabidores de guerra e muy osados.

134.-Por que las cosas secretas no dañen a la industria del capitan, conviene que inquiera primera mente todas las cosas.

135.-Muy buena cosa es con trabajo abrir los caminos estrechos en tanto que sean seguros.

136.-Mucho nos conviene saber ordenar lo que a nos es provechoso o nos muestra el contrario.

137.-Los caualleros nobles miran en derredor todas las cosas e non parten dellas mano fasta que son perfetas.

138.-Aquellos que son dichos ordenados para bien catar las cosas de cada parte que pertenesçientes e muy prouados son, que quiere dezir que aquel que verdadera mente es ofiçial, pertenesçiente es e muy prouado en su ofiçio.

139.-Esta palabra castillos quieren dezir huestes pequeñas.

140.-Graue cosa es el enemigo llegar a aquellos lugares en los quales sabe que los contrarios detras e delante estan.
131.-Prouisa non solent esse formidini. (III, VI, p 24, 3-4)

132.-Nam in campis patentibus equites magis solent inpugnare quam pedites. (III, VI, p. 25, 3-5)

133.-Praeponendi ergo sunt excercitatissimi campidoctores uicari uel tribuni, qui alacriores retardent... (III, VI, p. $25,7-8$ )

134.-Sed ne secreta noceant, ducis praestat industria, quem omnia prius conuenit explorare. (III, VI, p. 26, 3-4)

135.-Quod si angustae sunt uiae, sed tamen tutae, melius est [praecidere cum securibus ac dolatoriis milites et] cum labore uias aperire. (III, VI, p. 26, 8)

136.-Scire nos conuenit et ordinare quod nobis utile, illis docetur aduersum. (III, VI, p. 27, 3-4)

137.-(Tribuni) circumeunt nec ante discedunt qui strenui sunt quam fuerint uniuersa perfecta. (III, VIII, p. 34, 3-4)

138.-Idoneos tamen tribuni et probatissimos eligunt qui circumeant uigilias et renuntient si qua emerserit culpa,quos circumitores appellabant; nunc militiae factus est gradus et circitores uocantur. (III, VIII, p. 35, 6-8)

139. -Nam a castris diminutiuo uocabulo sunt nuncupata castella. (III, VIII, p. 36, 3-4)

140.-Difficile enim hostis ad ea loca audet accedere in quibus a fronte et a tergo nouit aduersarios commorari. (III, VIII, p. 36, 5-6) 
141.-Los buenos caualleros sienpre tientan non aquella batalla en la qual abierta mente ay peligro de amas partes, mas aquella en que el peligro es escondido.

142.-Son de señalar aquellas cosas nesçesarias que los antiguos fallaron que son las siguientes.

143.-Prouechosa cosa es al cabdillo que piense quien tiene mayor parte de omes de batalla su adversario o el.

144.-Yten, quales son mas armados - guarnidos los suyos o los otros.

145.-Yten, quales son mas vsados.

146.-Yten, quales son mas fuertes en las nesçesidades.

147.-Yten, quales tengan mejores omes a cauallo o a pie.

148.-Yten, los logares donde deuen pelear si son prouechosos a nos o a los enemigos, por que si mucha gente de cauallo tenemos to cai pos deuemos demandar.

149.-Sy mucha gente de pie tenemos, deuemos elegir los lugares estrechos e enbargados por cauas e lagunas e arboles.

150.-Yten, a quien abonda la vianda o a quien fallesçe por que la fanbre de dentro pelea e muchas vezes vençe syn fierro.

151.-E avn mas al cabdillo pertenesçe aquesto, proueer si es espidiente alongar la batalla o mas ayna la dar.
141.-Boni enim duces non aperto proelio, in quo est commune periculum, sed ex occulto semper adtemptant. (III, IX, p. 37, 1-2)

142.-Quae necessaria admodum sunt ab antiquis reperta prescribam. (III, IX, p. 3-, 3-4)

143.-Praecipua ars et utilitas ducis est ut (adhibitis ex uniuerso excercitu scientibus belli et sapientibus uiris) de suis et hostium copiis saepius tracter. (III, IX, p. $37,4-6)$

144.-Utrum ipsius an aduersariorum homines magis armati sint et muniti. (III, IX, p. 37, 7-8)

145.-Qui magis excercita.i (III, IX, p. 37,8 )

146.-Qui sint in necessitatibus fortiores. (III, IX, P. 37, 8-9)

147.-Quaerendum etiam utra pars equites, utra perites habeat meliores. (III, IX, p. 37, 9)

148.-Postremo loca ipsa in quibus pugnandum est, utrum inimicis an nobis uideantur adcommoda: nam si equitatu gaudemus, campos debemus optare. (III, IX, p. $38,2-3$ )

149.-Si pedite, loca eligere (debemus) angusta, fossis paludibus uel arboribus inpedita. (III, IX, p. 38 , 3-4)

150.-Cui magis uictus abundet aut desit; nam fames, ut dicitur, intrinsecus pugnat et uincit saepius sine ferro. (III, IX, p. 38, 4-5)

151.-Vel maxime autem tractandum est utrum expediat necessitatem protrahi an celerius dimicari. (III, IX, p. 38, 6-7) 
152.-Muchos quebrantados por trabajo e enojo desfallesçen.

153.-A las cosas menor fe es de dar si son contrarias.

154.-Mucho conuiene saber que tal es el enemigo e sus conpañeros, sy son arrebatados o cabtelosos o osados o temerosos o sy saben el arte de pelear o sy continuan pelear con locura e asi mesmo que gentes tienen fuertes o que couardes.

155.-Eso mismo las nuestras ayudas quanto valen o que fe tienen o de que fuerça son e que coraçones tiene la nuestra hueste $e$ qual parte della afyrma mas la vitoria.

156.-Ca de los semejantes pensamientos cresçe la virtud de la hueste o es quebrantada.

157.-Las buenas palabras de los capitanes fazen crescer osadia a los que desesperan si en ellos non paresçe temor.

158.-Mucho es de guardar de non traher a batalla publica la hueste que esta dubdosa e temerosa.

159.-Eso mismo acate al capitán si tiene omes mançebos o caualleros viejos e si por poco tienpo han estado en las faziendas o sy an estado por algunos años en paz.

160.-No deuen ser tomados por omes de armas los que por luengo tienpo han dexado de pelear.
152.-Tum fracti labore et taedio plurimi deserunt. (III, IX, p. 38, 9-10)

153.-Quia aduersis rebus rarior fides est. (III, IX, p. 38, 10-11)

154.-Ad rem pertinet, qualis ipse aduersarius uel eius comites optimatesque sint, nosse, utrum temerarii an cauti, audaces an timidi, scientes artem bellicam uel ex usu an temere pugnantes; quae gentes cum his fortes, quae ignauae sint. (III, IX, p. 38 , 11-p. 39, 1-3)

155.-Nostra auxilia cuius fidei quarumque sint uirium; quos animos illius copiae, quos habeat noster exercitus; quae pars sibi uictoriam repromittat. (III, IX, p. 39, 3-4)

156.-Eiusmodi enim cogitationibus uirtus augetur aut frangitur. (III, IX, p. 39, 5)

157.-Desperantibus autem crescit audacia adhortatione ducis et, si nihil ipse timere uideatur, crescit animus. (III, IX, p. 39, 5-6)

158.-Cauendum enim est ne dubitantem formidantemque exercitum ad publicam pugnam aliquando producas.(III, IX, p. 40, 1-2)

159.-Interest utrum tirones an ueteres milites habeas, et utrum ante breue tempus in expeditionibus fuerint an annis aliquot in pace durarint. (III, IX, p. 40, 2-3)

160.-Nam pro tironibus accipiendi sunt qui pugnare longo tempore desierunt. (III, IX, p. 40, 3-4) 
161.-Sy yerran en algunas cosas ysenlas e sean enseñados fasta tanto que sean perfectos.

162.-No deuen ser traydos a publica batalla en comienço, mas deuen antes ser acostunbrados en menores peleas.

163.-Otrosi el capitan deue ser velador sabio e mesurado, ca los menos e de menor fuerça faziendo çeladas e sobreuientas so buenos capitanes e muchas vezes ovieron asi vitorias.
161.-Si errant in aliquibus, exerceantur atque doceantur, quandiu pośsint esse perfecti. (III, IX, p. 41, 1)

162.-Ne sic quidem temere sed occasione capta ad publicam ducendi sunt pugnam, sed ante minoribus proeliis inbuendi. (III, IX, p. 41, 3-4)

163.-Dux itaque uigilans sobrius prudens...; nam pauciores numero et inferiores uiribus superuentus et insidias facientes sub bonis ducibus reportauerunt saepe uictoriam. (III, IX, p. 41, 4, 7-9) 


\section{NOTAS CRITICAS A LA VERSION CASTELLANA}

Título: Dichos de Séneca en el acto de la caualleria $T$ Dichos de Seneca en el fecho de la cauallería $M$ Aqui comiença el tratado de Seneca de la cauallería $N$ Aqui comiençan algunos dichos de Seneca en el fecho de la caualleria de rroma $V$.

1. cree $\alpha$ : creas $S$

2. E solo por esto $S:$ e por esto $T$ $V$ e por eso $N$ por esto $M$

3. E: om. $M$. breuedat $S$ : benignidat $T$ benignidad $M N V$. profia $\alpha$ : pofia $S$

4. mesmo: como $V$

5. afreos $N V$. riqueza $M$

6. E asi $M V$. artes $M N$ : arte $S$ antes $T$

8. quiere $S V$ : querria $T M N$. llamaua $M$. sçiençia $\alpha$ : justiçia $S$

9. ninguno $\alpha$ : ninguno noS. confiesa $V$

10. de $S:$ a $T M$ para $N$ om. $V$

12. los : om. $T N$. nasçidos : vençi$\operatorname{dos} N$
13. batallas $\alpha$ : peleas $S$. ha $\alpha$ : an $S$. ventajas $N$. vna gente de otra $T M N$ : vna gente a otra $V$ unas gentes de otras $S$.

14. sito $M N$. corporal mas avn para la fuerça $S T:$ om. $M N V$

15. desecadas : desatadas $V$. la mucha $S$ : el mucho $\alpha$. e por la poca $\alpha$ : e poca $S$. de pelear: om. $M$. de otra : por otra $T M$

16. Non T M . septentrional $\alpha$ [setentrional $N V]:$ om. $S$

17. Tenplada $S$ : tenprada $\alpha$. fallesçen $M$. de sangre $S:$ de gente $\alpha$. nin : om. $M$. pueda $T M$

18. castillos $\alpha$ : castigos $S$. consejo : om. $N$. que post consejo add. $S$ 
19. pueblo rustico $S$ : rrustico publico $\alpha$. acto $M N$. curando $V$. baños : vmanos $M$. duros: dignos $V$. todos los males al qual leuar: om. $M$. cauas $\alpha$ : armas $S$. es de $M$ $N V$ : es $T$ ha de $S$.

22. $\operatorname{son} \alpha: \operatorname{son}$ bien $S$. es $S$ : es el temor de dios $\alpha$.

23. tr : tenprar $V$

24. guerrero $S T$ : garguero $M N V$

25 . ser causa de non $S:$ ser cansado non $T$ ser casado con $M N$ $V$. aver : aviendo $M$. que non que : que non $T$, aquella : aquella hedat $N V$

26. manda $S$ : demanda $\alpha$. se : om. $T$. demande $S V$ : demanda $T$ $M N$. estatura : astuçia $V$

28. Es de $S$ : es a $\alpha$. de veladores $T$. dedos $S$ : cabdos $\alpha$. pequeno vientre $\alpha$ : pequeños vientres $S$. demasiada : demasia demasia de $M$. cargada $V$.

29. cosa : mente $T$

30. salud de toda la republica $M N$ $V$ : salud toda de la república $S$ salud de toda la hueste $T$. e muy sabidores post coraçones add.S.

34. deuen $S M N V$ : conuiene $T$. los más mançebos $\alpha$ : los mançebos $S$

35. prueuan $S T$ : prueua $M N V$

36. non aprouecha tanto $N$. muchedunbre : mansedunbre $V$

40. ms : om. $N$. cosas de otros que $\alpha$ : cosas que de otros $S$. escriue $N$

41. muy : mucho $T$. es : om. $N$. acaesçier $T$.
42. abundançia de $\alpha$ : om. $S$. asaz $S$ $T:$ om. $M N V$. de $S \mathrm{~N}$ : en $T$ $M V$

43. abaxa $S T$ : abaxo $M N V$. nos : om. $M$. faga $S$ : fiziese $\alpha$. sojudga $S$ : sojudgo $\alpha$

44. de las batallas $S V$ : de la batalla $T M N$. punto : tienpo $M$

45. peresçen $S M N$ : paresçen $V$ paresçe $T$. o syn $S$ : osen $N$ osan $T V$ asen $M$. pelean $S$ : pelear $\alpha$. o dados $\alpha$ : vsados $S$ . vso e $\alpha$ : vso $S$. el saber : por el saber $V$ el sabe $N$

47. 48. desanparados [desmanparados $V]$ e desarmados $\alpha$ : desarmados $S$. a las feridas $\alpha$ : om. $S$

49. trabajoso $S T$ : trabajo $M N V$.

50. armado $S T$ : armada $M N V$. ca post cuerpo add. $S$

51. fuere $\alpha$ : estouiere $S$. estouieren $S T N$ : estudieren $M V$. en uilla çercada : en lugar çercado $M$.

52. a su $S M:$ su $T N V$

53. cura : carga $V \cdot \operatorname{ser} \alpha: o m$. $S$. con : en $V$. e om. $T$

54. e om. $N$. cuesta $S$ : cuesta de $\alpha$ - agenes : suyos $M$

58. nueuas: muelles $\mathrm{V}$. sobrepuje $T$. la $S$ : a la $\alpha$.

60. es la : es $N V$

61. exerçito $S T$ : exerçiçio $M N V$ - quiere $\alpha$ : que quiere $S$. de guerra e $S:$ om. $\alpha$. e por que $S$ : por que $\alpha$. tomo : toma $N$. nonbre $S N$ : nombrado $T$ nonbrando $M V$. 
62. los que $S:$ lo que $\alpha$. desacuerdan $S$ : discuerdan $T$ discuerda $M N V$.

63. aproueche $S T M$ : aprouechen $N$ aprouechan $V$. todos $S$ : tomados $\alpha$ regidores $N$. lo que les : los quales $V$.aquellos : a aquello $M$. en ante $S T$ : de ante $M N V$. no: om. $M$

64. ocupen $T$. por gracia $S$ : grandes $\alpha$. solia $M$.

65. son : om. $T$. eternales $M N$.

66. acatados $S$ : açebtados [açepta$\operatorname{dos} N] \alpha$.

67. mal : bien $V$.

68. non se deue $S$ : non deue $\alpha$. contar $S:$ ser contada $M N V$ contra $T$. actor $\alpha$ : acto $S$.

69. pueden $T$. conprehendidas $S$ : aprendidas $\alpha$. memoria : manera $N$. atento $S$ : apretado $T$ atenprado $M N V$.

70. jurar $T$. el linaje $S$ : e el linaje $\alpha$. deue $M N$. mantener e onrrar $S$ : mantener onrra [honrra $M] T M N$ guardar e mantener honrra $V$.

71. es $S:$ on. $\alpha$. dios : $\operatorname{dos} M$. presente en cuerpo $\alpha$ : presente $S$.

72. cauallero o otro cualquier $T N$ $\therefore$ cauallero otro qualquier $M V$ cauallero $S$. sirue a dios-el enperador : om. $M$. e esto : esto $S$.

73. mesurado $S$ : mesurado e $\alpha$, a el : aquel $N$.

74. fazer : $\operatorname{ser} N$.

76. rentas $M$. e $S T$ : om. $M N V$.

77. acabdilla $S$ : ha [a $N$ ] cabido en $\alpha$. conpaña : virtud $M$. armas : om. $M$.
78. que : aquel que $T M$. por : om. $N$. dexan $M$.

79. caualgadores $T N V$ : caualdores $S$ caualgados $M$. mas avn $\alpha$ : mas.. ..avn $S$. cauallos : caualleros $M N$. enseñar : sayar $M$. contynuo : contrario $M$.

80. de : que de $T N$. siga $S T$ : non siga $M N V$.

82. restituye : refuye $M$.

83. peresçe $M$.

84. toda cosa que quiere $S$ : todo lo que quisiere quisier $[T] \alpha$.

85. no $S$ : om. $\alpha$. ser : om. $T$. sostenido : sustentado $V$. vistuario : sostuario $N$. en su $S T$ : a su $M N V$. interese $S: o m$. $\alpha$.

86. despiden $N$.

88. instinto $\alpha$ : mandamiento $S$. todas las : om. $N$. paresçia $S V$ : paresçe $T$ paresçen $M N$.

91. ferir el $\alpha$ : estar al $S$. delante $S$ $T:$ om. $M N V$.

92. acaesçe : om. $M$.

94. mal: mas $M N$.

95. de la guerra $\alpha$ : om. $S$. sea $M V$ - cargosos $S T$ : cargoso $N V$ trabajoso e cargaso $M$.

96. della $M$. en pas $V$. se le $N$.

97. vsado $M V$ : vsando cett. . reçela : desea $V$.

98. en la : en $V$.

101. por la $S:$ om. $\alpha$

104. maravillosa mente $S$ : omillmente [vmillmente $T$ ] e marauillosa mente $\alpha$. 
105. quisiere $S T$ : fiziere $M N V$. mediania $S$ : medianeria $T N V$ medianera $M$. de los actores $\alpha$ : om. S . conviene $S$ : prueua $T$ $M$ prueba $V$ prouea $N$. sea $\alpha: o m s$.

106. apareje $S T$ : apreste $M N V$.

107. cobdiçie $T$.

108. por arte $e$ non por aventura ni arte $T$

109. para: por $T$. perseguir $S:$ enseñar $\alpha$. le $S:$ lo $T M N$ om. $V$

111. paresçer $T$.

112. muchedumbres $M$. que : om. $M$ $N$

113. calor: saber $T$.

116. abastado $S:$ basteçido $\alpha$

117. muchas vezes $\alpha$ : algunas vezes $S$. mas dura la çerca do mas dura la çerca $T$.

119. muchos son que $T$. a las guerras $T$.

120. despanta $T N$. enfia $M N$. de la guerra $M N$.

121. vienen: biuen $T$. e por $T$. esperan $S$ : esperauan $T M N$ esperaban $V$. e de sus delictos $\alpha$ om. $S$.

123. son de loar mas $N$. o $S:$ e $T$ $M N$ y $V$.

124. se om. $M .126-163$ om. $V$.

126. seguro $S$ : segura cosa $T M N$. se ha $T M N$ : se a $T$.

127. acaeçe $\alpha:$ om. $S$. que post vezes $T M N$

128. muy $a:$ om. $S$. argumentados $T$ : argumentadores $M N$ juramentados $S$. ysquierda e a la derecha $S$ acatan $T$.
129. frente $S$ : fruente $M N$ fuente $T$; de las $S M$ : por las $T N$.

130. dañe $S$ : deuen $\alpha$. de : om. $M$ $N$.

131. suelen $S T$ : deuen $M$ pueden $N$.

132. los caualleros $S:$ los de cauallo $\alpha$.

133. en los canpos $S$ : en el canpo $\alpha$ . de poner : om. $N$. vsados $M$

134. inquiera $S$ : inquieran $\alpha$. primera mente : primero $N$.

135. estrechos $S$ : çerrados e estre$\operatorname{chos} \alpha$. en $\alpha: \operatorname{con} S$.

138. dichos $M N$ : muchos $S T$. que aquel que $\alpha$ : que aquel...que $S$ - prouado: priuado $M$.

139. Esta palabra $\alpha$ : estas palabras $S$. que post castillos add. $S$. quieren $S T$ : quiere $M N$.

140. Sabe $S T$ : saben $M_{1} N$.

141. sienpre tientan non $\alpha$ : non temen $S$. abierta mente ay [han $N$ ] peligro $\alpha$ : esta conosçido el peligro $S$. aquellas $T$.

142. señales $N$.

144. mas $S:$ mejor $T$ om. $M N$. o guarnidos $S:$ om. $\alpha$.

145. vsados $M$ : osados cett. .

148. donde $S T$ : en que $M N$, a nos $T N$ : a $\operatorname{vos} M$ años $S$. en los canpos $T$.

149. tenemos $\alpha:$ om. $S$.

150. o a quien $S: \circ \alpha$.

151. alongar $S N$ : de alongar $T M$ - mas ayna la dar $S$ : mas ayna dar la $M N$ mas ayudarla $T$.

153. A las cosas----contrarias $S:$ a los contrarios menor fe es de dar $M N$ a los contrarios mejor fee es de dar $T$. 
154. de saber $M$. sy $S T$ : o sy $M N$ - continuan $S$ : costunbran $N$ conturban $T$ conturba $M$. asi: esto $M$. o que $\alpha:$ o $S$.

155. e que $S M$ : e que $T N$. o de $S$ : e de $\alpha$. tiene $T N$ : tienen $S$ $M$. della $M N$ : dellas $S T$.

156. cresçe $S:$ rrecresçe $\alpha$.

157. ellas $M$.

158. dubdosa e temerosa $\alpha$ : temerosa e dubdosa $S$.

159. e si $T$ : o si $S N$ e $M$. estado $S$ : vsado $M N$ vsados $T$.
161. vsenlas e sean enseñados fasta tanto que $\alpha$ : vsenlo fasta que sean tanto enseñados que $S$.

162. No $S$ : en non $\alpha$. en comienço $S$ :om. $\alpha$. antes $S N$ : om. $T M$.

163. deue ser $\alpha:$ om. $S$. sabio e mesurado $S$ : mesurado e sabio $T$ mesurado sabio $M N$. sobreuientas $S M$ asobrevientas $T N$. so coni.: son codd. capitanes $\alpha$ : om. $S$. asi $S N$ : om. $T$ $M$. victoria $M$.

Aqui se acaba el libro de la guerra $S$. 